\title{
An ecogenomic analysis of herbivore-induced plant volatiles in Brassica juncea
}

\author{
VARTIKA MATHUR, ${ }^{1}$ TOM O. G. TYTGAT,$\dagger^{1}$ CORNELIS A. HORDIJK, \\ HARRY R. HARHANGI,§ JEROEN J. JANSEN, $₫$ A. SANKARA REDDY,** JEFFREY A. HARVEY, \\ LOUISE E. M. VET $+\dagger \dagger$ and NICOLE M. VAN DAM† \\ *Department of Zoology, Sri Venkateswara College, University of Delhi, Benito Juarez Marg, Dhaula kuan, New Delhi 11002, \\ India, †Department of Ecogenomics, Institute for Water and Wetland Research, Radboud University, Heyendaalseweg 135,6525 \\ AJ Nijmegen, The Netherlands, \$Department of Terrestrial Ecology, Netherlands Institute of Ecology, PO Box 50,6700 AB \\ Wageningen, The Netherlands, §Department of Microbiology, Institute for Water and Wetland Research, Radboud University, \\ Heyendaalseweg 135, 6525 AJ Nijmegen, The Netherlands, qDepartment of Analytical Chemistry, Radboud University \\ Nijmegen, Heyendaalseweg 135, 6525 AJ Nijmegen, The Netherlands, **Rai University, Saroda Post, Dholka Taluka, Ahmedabad \\ district, Gujarat 382260, India, ††Laboratory of Entomology, Wageningen University, PO Box 8031, 6700 EH Wageningen, The \\ Netherlands
}

\begin{abstract}
Upon herbivore feeding, plants emit complex bouquets of induced volatiles that may repel insect herbivores as well as attract parasitoids or predators. Due to differences in the temporal dynamics of individual components, the composition of the herbivoreinduced plant volatile (HIPV) blend changes with time. Consequently, the response of insects associated with plants is not constant either. Using Brassica juncea as the model plant and generalist Spodoptera spp. larvae as the inducing herbivore, we investigated herbivore and parasitoid preference as well as the molecular mechanisms behind the temporal dynamics in HIPV emissions at 24, 48 and $72 \mathrm{~h}$ after damage. In choice tests, Spodoptera litura moth preferred undamaged plants, whereas its parasitoid Cotesia marginiventris favoured plants induced for $48 \mathrm{~h}$. In contrast, the specialist Plutella xylostella and its parasitoid C. vestalis preferred plants induced for $72 \mathrm{~h}$. These preferences matched the dynamic changes in HIPV blends over time. Gene expression analysis suggested that the induced response after Spodoptera feeding is mainly controlled by the jasmonic acid pathway in both damaged and systemic leaves. Several genes involved in sulphide and green leaf volatile synthesis were clearly up-regulated. This study thus shows that HIPV blends vary considerably over a short period of time, and these changes are actively regulated at the gene expression level. Moreover, temporal changes in HIPVs elicit differential preferences of herbivores and their natural enemies. We argue that the temporal dynamics of HIPVs may play a key role in shaping the response of insects associated with plants.
\end{abstract}

Keywords: gene expression, green leaf volatiles, mustard, parasitoids, Spodoptera, sulphides

Received 22 May 2013; revision received 23 September 2013; accepted 27 September 2013

\section{Introduction}

Plant volatiles play an important role in a range of ecological processes in natural communities. These include

Correspondence: Vartika Mathur, Fax: +91-11-24118535;

E-mails: vmathur@svc.ac.in, vartika_m@yahoo.com

${ }^{1}$ Both authors contributed equally to this manuscript. mediating interactions with neighbouring plants, herbivores, carnivores, mutualists and microbes (van Dam 2009). The composition of the emitted volatiles changes qualitatively and/or quantitatively upon insect herbivory (Dicke \& Vet 1999; Paré \& Tumlinson 1999; Arimura et al. 2009; Dicke \& Baldwin 2010). These so-called herbivore-induced plant volatiles (HIPVs) attract the herbivores' natural enemies, deter other herbivores 
from ovipositing on the plant and prime neighbouring plants (Dicke \& Baldwin 2010). Herbivores and their natural enemies rely on the specificity of the HIPV blend to increase their chances of finding a suitable host plant or prey (Vet 1999; Dicke \& Baldwin 2010). For instance, they play an important role in enabling parasitoid wasps to locate their preferred host species and the most suitable larval stage for the development of their offspring (De Moraes et al. 2001; Holopainen 2004; Vuorinen et al. 2004; Gols et al. 2011). Many laboratory studies have demonstrated that HIPVs make plants more attractive to host-seeking natural enemies (van Poecke et al. 2003; Turlings \& Wäckers 2004; de Boer et al. 2008; Gols et al. 2012), and field studies corroborate the role of HIPVs in the attraction of natural enemies towards induced plants (De Moraes et al. 1998; Kessler \& Baldwin 2001; James \& Grasswitz 2005).

Herbivore-induced plant volatile blends are chemically very diverse. Globally, the compounds in these blends can be categorized into three classes according to their biosynthetic origin (Arimura et al. 2009): (i) fatty acid-derivatives, called green leaf volatiles (GLVs), which are $\mathrm{C}_{6}$ aldehydes, alcohols and their derivatives, as well as jasmonic acid (JA), which is produced by the lipoxygenase (LOX) pathway. GLVs are produced via the hydroperoxide lyase (HPL) pathway, which is a component of the LOX pathway; (ii) terpenoids, which are synthesized via the mevalonate and the nonmevalonate (also called as methylerythritol phosphate or MEP) pathways; (iii) aromatic volatiles derived from the shikimic acid pathway, such as indole and methyl salicylate (Holopainen 2004; Conti et al. 2008). Once the basic skeleton of these small-molecular-weight compounds is produced, their diversity is further increased by modifications such as acylation, methylation, oxidation/reduction and cyclic ring closure. Such modifications often result in increased volatility and changed olfactory properties (Pichersky et al. 2006).

One of the best studied plant families in terms of HIPV composition and function is Brassicaceae (Hopkins et al. 2009). This family includes many important crop species, such as various cultivars of mustard and cabbage, as well as a large diversity of wild species with a worldwide distribution (Warwick et al. 2006; Franzke et al. 2011). Brassicaceae are characterized by the production of secondary metabolites known as 'glucosinolates' (Hopkins et al. 2009). Upon herbivory, glucosinolates are hydrolysed by the enzyme myrosinase and yield volatile products such as nitriles and (iso) thiocyanates, depending on the reaction conditions (Wittstock et al. 2003). These hydrolysis products are associated with direct plant resistance strategy against various insects and pathogens (van Dam et al. 2009; Gols \& Harvey 2009; Hopkins et al. 2009; Mathur et al.
2011), but can also serve as cues to natural enemies specialized on Brassica herbivores (Smid et al. 2002; Gols et al. 2008, 2011). The glucosinolate hydrolysis products can be further degraded, thus forming additional volatile sulphur compounds (Attieh et al. 2000a). These sulphur-containing compounds, along with other volatiles of the above-mentioned three volatile classes, contribute to the typical 'Brassica odour'.

Many studies have applied molecular techniques to unravel processes by which plants perceive insect attack and trigger HIPV emissions (Arimura et al. 2005; De Vos et al. 2007; Soler et al. 2012). Similar to other herbivore-induced responses, the emission of HIPVs is mainly controlled by the phytohormones JA, salicylic acid (SA) and ethylene (ET; Gatehouse 2002; Howe \& Schaller 2008; Dicke \& Baldwin 2010). Based on herbivore-derived external cues, such as salivary compounds and feeding strategies, a specific combination of these hormones is produced (De Vos et al. 2005; Ehlting et al. 2008). JA is mainly involved in the regulation of induced plant responses against wounding and herbivory (Koo \& Howe 2009; Koo et al. 2009). Crosstalk between signalling pathways helps the plant to finetune its defence response to the invaders encountered (Pieterse \& Dicke 2007; Koornneef \& Pieterse 2008; Verhage et al. 2010; Pieterse 2012). In general, ET and JA act synergistically, while SA is known to act antagonistically on JA signalling (Adie et al. 2007; Koornneef \& Pieterse 2008; Verhage et al. 2010). Hence, the functional outcome is determined by a complex regulatory network and is highly tissue and context specific (Pieterse 2012). Molecular tools such as qPCR now make it possible to directly link gene expression to the emission of HIPVs and insect behaviour (Halitschke \& Baldwin 2003; Kessler \& Baldwin 2004; Skibbe et al. 2008; Gosset et al. 2009; Zhang et al. 2013). These studies have shown that the production of HIPVs involves the activation of an intricate network of different genes in the hormonal signalling pathways above as well as biosynthetic genes involved in the production of various HIPV classes (Attieh et al. 2002; Zheng et al. 2011). The expression of many of these genes differ in time, illustrating the dynamic interplay between genes involved in signalling pathways and defence compound production (Koornneef \& Pieterse 2008; Broekgaarden et al. 2010; Erb et al. 2012; Kerchev et al. 2012; Zhang et al. 2013).

Indeed, HIPV emissions are known to be highly dynamic (De Moraes et al. 2001). The blend of volatiles quickly changes within a short time span of days or even hours after onset of the damage. However, studies analysing ecological functions of HIPVs may not account for this dynamics. Usually one selects a time point for which the volatile emissions and the response of the insect of interest are maximized, thereby ignoring 
the natural temporal dynamics of the induction process. Thus far, few studies have demonstrated temporal changes in HIPV emission and discussed their possible ecological role (Schmelz et al. 2003; Bruinsma et al. 2009). Moreover, different herbivores and their parasitoids may respond differently to temporal changes in the HIPV blend, as they may have different levels of specialization on the host plant. In this study, we correlate the temporal variation in HIPV blends and their corresponding molecular mechanisms with the preference of insects at different trophic levels to gain a more comprehensive insight into the exact role of HIPVs in the communication between plants and associated insects. This knowledge is essential to elucidate which ecological costs and benefits are associated with the production of HIPV in time and hence to better understand whether there is indeed a net value for the plant.

We explicitly link temporal patterns of HIPV emissions to their corresponding gene expression patterns and the preference of generalist and specialist herbivores as well as their natural enemies. We thereby hypothesize that herbivores will prefer undamaged plants as these provide an uninduced resource without competition by other herbivores. On the other hand, their natural enemies are expected to prefer plants that have been damaged for the longest time period, because we expect that volatile emissions will increase with time and amount of damage. To test these hypotheses, choice experiments were performed with the generalist herbivore Spodoptera litura Fabricius (Lepidoptera: Noctuidae) and the specialist Plutella xylostella L. (Lepidoptera: Plutellidae) as well as their parasitoids Cotesia marginiventris Cresson and C. vestalis Kurdjumov (previously known as C. plutellae; Hymenoptera: Braconidae), respectively. These insects were offered plants that had been damaged by Spodoptera spp. for 24,48 or $72 \mathrm{~h}$ or were undamaged. The expression of genes involved in hormone signalling (MYC2, VSP2, ERF1, ETR1 and PR1), HIPV (TPS10, TPS21, CYP82G1, HPL1, ChlADR, CHAT and TMT1) and glucosinolate biosynthesis (CYP79B2, CYP79F1, CYP83A1), and HIPV profiles of similarly treated plants were analysed at corresponding time points. This combined approach provided us a comprehensive view on the temporal dynamics of mechanisms and ecological function of HIPVs in plants.

\section{Materials and methods}

\section{Plants}

Seeds of Brassica juncea var. varuna were obtained from the Division of Genetics, IARI, New Delhi, India, in 2008 and stored dry and in the dark at $10^{\circ} \mathrm{C}$. They were germinated on glass beads in water in $10 \times 10 \mathrm{~cm}$ plastic containers with a clear plastic lid. The greenhouse was kept at $21{ }^{\circ} \mathrm{C}$ during the day and $16{ }^{\circ} \mathrm{C}$ at night, under ambient light conditions that were supplied by sodium lamps to maintain the minimum PAR at $225 \mu \mathrm{moles} / \mathrm{m} / \mathrm{s}$ for at least $16 \mathrm{~h}$. Seven days later, seedlings were transferred to $1.8-1$ pots, containing $1000 \mathrm{~g}$ peat soil-sand mixture [Lentse Potgrond no. 4, Lent, the Netherlands (NL)]. From third week onwards, plants were supplied with 0.5 Hoagland solution (Hoagland \& Arnon 1950) once a week.

\section{Insects}

Egg batches of beet armyworm (Spodoptera exigua Hübner; Lepidoptera: Noctuidae) and pupae of the parasitoids Cotesia marginiventris and C. vestalis were obtained from the Department of Entomology, Wageningen University, NL. They were maintained in a climate room at $27{ }^{\circ} \mathrm{C}, 50-70 \% \mathrm{RH}$ and a 16-h light/-8 h dark photoperiod. A culture of $S$. exigua was maintained on an artificial diet as described by Vickerman \& Trumble (1999). Unmated naive females of herbivores and parasitoids were used within $24 \mathrm{~h}$ of emergence.

\section{Induction of plants}

All the experiments were performed when the plants were approximately 4 weeks old and in stage 63 according to BBCH scale (Lancashire et al. 1991). A single fourth instar of S. exigua larva was introduced in a 6-cm-diameter clip cage to the fourth leaf counted from the apex of the plant. Depending on the treatment group, larvae were allowed to feed for 24,48 or $72 \mathrm{~h}$. Undamaged plants received empty clip cages. To avoid positional bias, damaged and undamaged plants were randomly placed on the greenhouse tables.

\section{Insect preference}

In contrast with all other experiments, which were performed in NL, the herbivore preference bioassay was performed in India at Sri Venkateswara College, University of Delhi, Delhi. There, plants were grown in earthen pots using garden soil in an insect-free enclosure. To obtain similar environmental conditions (light, temperature) as in NL, the experiments were performed from October until the beginning of December. Spodoptera exigua was not available in India, and transport of live insects between both countries is not allowed because of quarantine regulation. Therefore, the plants were induced using third instar larvae of Spodoptera litura as above in similar clip cages as in NL, after which the preference of adult S. litura and Plutella xylostella was tested. Earlier studies have revealed similar 
extent and timing of induction of various traits due to herbivory by S. litura and S. exigua in B. juncea in both countries (Mathur et al. 2011). Larvae of S. litura and $P$. xylostella were obtained from laboratory cultures maintained at Sri Venkateswara College on castor bean and cabbage leaves, respectively. The adults of both S. litura and P. xylostella are nocturnal, and therefore herbivore orientation preference experiment was conducted at night. All other experimental procedures for the preference bioassays were performed in an identical way in India and NL.

The parasitoid preference experiments were performed in NL in full daylight when both C. marginiventris and $C$. vestalis are the most active.

To observe herbivore and parasitoid preference, an $X$-shape plexiglass olfactometer set-up was constructed that included a cylindrical releasing chamber of $20 \mathrm{~cm}$ diameter and $9 \mathrm{~cm}$ height (Fig. S1, Supplementary information). The floor of the chamber had an opening of $1.5 \mathrm{~cm}$ diameter for introducing the insects, which was closed with a rubber stopper. Four detachable cylindrical arms, each of $17 \mathrm{~cm}$ length and $5 \mathrm{~cm}$ diameter wide were fixed to the chamber at 90 degrees of angles. The other end of these arms was closed using a net.

For both herbivore and parasitoid preference experiments, plants were damaged 24,48 or $72 \mathrm{~h}$ prior to the beginning of the experiment. In this way, these plant treatments groups, along with the undamaged plants, could be presented simultaneously. Feeding herbivores were removed from the leaves prior to the beginning of the experiment. Whole potted plants were placed on either arm of the olfactometer so that plant volatiles could diffuse through the arm closest to the plant. The experimental set-up was placed outside at temperatures ranging from 23 to $26^{\circ} \mathrm{C}$ in a tent $(100 \times 70 \times 70 \mathrm{~cm})$ covered with fine mesh gauze.

In total, 116, 48, 140 and 55 biological replicates of S. litura, P. xylostella, C. marginiventris and C. vestalis, respectively, were used. Cohorts of herbivore or parasitoid females were released in groups of five from the bottom of the chamber and observed after $15 \mathrm{~min}$. If a female was found to have moved up to the end of an arm, it was recorded as making a choice for the corresponding plant. If a female did not make a choice, it was excluded from analysis. After testing five females, the plants were moved to another position to avoid any positional bias and the arms of the olfactometer were cleaned with ethanol. After four replicates of five females each, the test plants were replaced by new ones.

\section{Volatile analysis}

Due to technical limitations of the volatile collection equipment, not all biological replicates at a certain time point could be analysed simultaneously. Therefore, we divided the induced plants into three batches that were induced and analysed at different time points, over a total time period of 5 days according to the diagram shown in Fig. 1. Clip cages, along with the S. exigua larvae, were removed prior to volatile sampling and immediately put back thereafter. The damaged plants, 12 biological replicates in total, were repeatedly measured at 24, 48 and $72 \mathrm{~h}$ after damage in three partly overlapping series over 5 days. The undamaged plants, three biological replicates in total, were repeatedly measured on all 5 days of the experiment to control for temporal and ontogenetic variation.

Prior to the experiment, turkey roasting bags (Toppits, Melitta Nederlands BV, Gorinchem, NL), $25 \times 40 \mathrm{~cm}$, were heated at $120{ }^{\circ} \mathrm{C}$ for $2 \mathrm{~h}$ in an oven (as per Stewart-Jones \& Poppy 2006). Bags were individually placed around a single leaf that was subjected to larval treatment in damaged plants or a leaf of similar age on undamaged plants. The bag was fitted with a steel trap that was placed just above the leaf. Volatiles were collected by pulling the headspace air with a vacuum pump over the trap filled with $150 \mathrm{mg}$ Tenax TA and $150 \mathrm{mg}$ Carbopack (Markes International Ltd., Llantrisant, UK). Flow rates over the traps were set to $100 \mathrm{~mL} / \mathrm{min}$ using mass flow regulators (Sho rate TM, Brooks Instrument, Hatfield, PA, USA). After $60 \mathrm{~min}$, the traps were removed, capped and stored at $4{ }^{\circ} \mathrm{C}$ until analysis. Four plants were sampled in parallel, and each day one background volatile profile from an empty bag was sampled. Volatiles were desorbed from the traps and analysed by GC-MS using the method and reference compounds described by van Dam et al. (2010). All integrated signals were generated from the MS chromatograms by the AMDIS software (NIST, USA). To correct for minor differences in sampling time and flow rates over individual traps, peak areas obtained in each sample were divided by the total

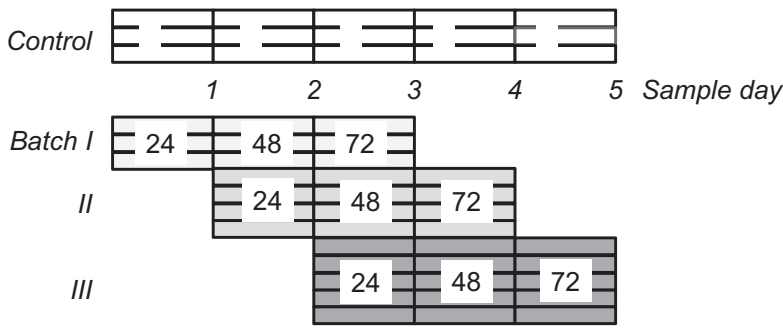

Fig. 1 Experimental design for volatile collection. The plants were used in three batches: Batch I, II and III had 3, 4 and 5 damaged plants, respectively (indicated by small rectangles in boxes). The same three undamaged plants were used in the whole experimental period. The numbers inside the boxes indicate time for which damage has occurred (in hours), and the number outside the boxes represent the day of the sampling. 
volume (in $\mathrm{mL}$ ) collected over the trap. Peaks related to mixtures of volatiles and impurities were removed from the data set. Background volatiles were uniformly subtracted from the volatiles of both undamaged and damaged plants to obtain volatiles emitted only by the leaves. To remove day-to-day variation on the five experimental days, for each day of sampling the logarithmic fold changes in emission of individual volatile compounds were calculated by the formula: $\ln$ [treatment (peak area +1$) /$ control (peak area +1$)$ ]. Thereafter, the obtained fold changes for each sampling day were averaged (Table 1).

\section{Gene expression analysis}

We investigated the temporal expression of genes in local (fourth leaf from the apex where larva was introduced) as well as systemic (third leaf from the apex) leaves to match both volatile measurements performed on local leaves and insect preference experiments performed on the whole plant. Plants were damaged using a fourth-instar S. exigua larva in a clip cage. Control plants received empty clip cages. To analyse the hormonal pathway induced by herbivore feeding, an additional batch of plants were induced by ectopic

Table 1 Mean \pm SE of the fold changes of volatile emissions calculated as $\ln$ [treatment $(X+1) /$ control $(X+1)]$ per day of sampling ( $n=3$ per time point per day, in total $n=9$ per time point). $\mathrm{X}=$ peak area of the compound. Values in bold represent significant changes in volatile emissions over controls $(P<0.05$ after independent-sample $t$-test $)$

\begin{tabular}{|c|c|c|c|c|c|c|}
\hline No. & Compound name & $\begin{array}{l}\text { LRI } \\
\text { (RTX-5 ms)* }\end{array}$ & $\begin{array}{l}\text { Compound } \\
\text { class }\end{array}$ & $\begin{array}{l}\text { Mean } \pm \text { SE fold } \\
\text { changes ln } \\
(X+1) 24 \mathrm{~h}\end{array}$ & $\begin{array}{l}\text { Mean } \pm \text { SE fold } \\
\text { changes ln } \\
(X+1) 48 \mathrm{~h}\end{array}$ & $\begin{array}{l}\text { Mean } \pm \text { SE fold } \\
\text { changes } \ln (X+1) 72 \mathrm{~h}\end{array}$ \\
\hline 1 & 1-Butene-4-isothiocyanate & 979 & Isothiocyanate & $4.33 \pm 1.02$ & $4.72 \pm 1.02$ & $6.54 \pm 0.59$ \\
\hline 2 & 2 - $\beta$-Pinene & 971 & Monoterpene & $-0.31 \pm 0.15$ & $0.33 \pm 1.33$ & $-0.84 \pm 0.46$ \\
\hline 3 & $\alpha$-Pinene & 927 & Monoterpene & $-0.57 \pm 1.35$ & $0.48 \pm 1.45$ & $-0.46 \pm 1.17$ \\
\hline 4 & 1-Monoterpene ${ }^{\dagger}$ & 1007 & Monoterpene & $-1.73 \pm 0.87$ & $-0.89 \pm 1.80$ & $-2.00 \pm 0.80$ \\
\hline 5 & Limonene & 1026.5 & Monoterpene & $0.51 \pm 0.49$ & $-0.38 \pm 0.69$ & $-0.67 \pm 0.12$ \\
\hline 6 & $\beta$-Ocimene & 1048.8 & Monoterpene & $-2.57 \pm 1.87$ & $-3.01 \pm 1.73$ & $-0.27 \pm 1.52$ \\
\hline 7 & $\alpha$-Copaene & 1371 & Sesquiterpene & $0.25 \pm 0.76$ & $-0.48 \pm 0.66$ & $0.30 \pm 0.69$ \\
\hline 8 & E,E-alpha farnesene & 1506.4 & Sesquiterpene & $1.67 \pm 0.94$ & $0.67 \pm 0.53$ & $0.10 \pm 0.10$ \\
\hline 9 & $\begin{array}{r}\text { (E,E)-4,8,12-trimethyl-1,3,7, } \\
\text { 11-tridecatetraene (TMTT) }\end{array}$ & 1577 & Homoterpene & $4.45 \pm 1.30$ & $2.00 \pm 1.12$ & $1.69 \pm 1.03$ \\
\hline 10 & $\begin{array}{l}<3 \mathrm{E}>-4,8 \text {-dimethyl-1,3 } \\
\text { 7-nonatriene }(\mathrm{DMNT})\end{array}$ & 1117 & Homoterpene & $3.10 \pm 1.59$ & $0.48 \pm 0.48$ & $1.93 \pm 0.41$ \\
\hline 11 & 3-Hexen-1-ol & 851 & GLV & $3.10 \pm 1.58$ & $4.22 \pm 0.86$ & $4.89 \pm 0.89$ \\
\hline 12 & 3-Hexen-1-ol-acetate & 1008 & GLV & $1.42 \pm 0.43$ & $1.20 \pm 0.19$ & $2.14 \pm 0.38$ \\
\hline 13 & Acetaldehyde ${ }^{\ddagger}$ & 498 & GLV & $-0.77 \pm 0.36$ & $3.50 \pm 1.88$ & $0.97 \pm 1.88$ \\
\hline 14 & Acetic acid ethyl ester & 600 & GLV & $1.43 \pm 1.26$ & $0.35 \pm 1.55$ & $-0.56 \pm 2.91$ \\
\hline 15 & Acetic acid hexyl ester & 1015.6 & GLV & $0.66 \pm 2.25$ & $1.03 \pm 1.03$ & $3.12 \pm 1.73$ \\
\hline 16 & Hexadecanoic acid methyl ester & 1928.6 & GLV & $0.94 \pm 0.62$ & $0.31 \pm 0.80$ & $-0.94 \pm 0.62$ \\
\hline 17 & Dimethyldisulphide & 738.8 & Sulphide & $0.33 \pm 0.14$ & $0.27 \pm 0.29$ & $0.42 \pm 0.18$ \\
\hline 18 & Dimethyltrisulphide & 961 & Sulphide & $0.57 \pm 1.43$ & $2.35 \pm 1.91$ & $2.60 \pm 1.13$ \\
\hline 19 & Salicylic acid hexyl ester & 1673.5 & SA & $-0.33 \pm 0.86$ & $-1.39 \pm 0.65$ & $-1.98 \pm 0.29$ \\
\hline 20 & 1-Dodecanol & 1474 & Alcohol & $-1.84 \pm 1.90$ & $-0.96 \pm 1.64$ & $-1.41 \pm 1.35$ \\
\hline 21 & 1-Tetradecanol & 1675 & Alcohol & $1.91 \pm 0.99$ & $0.31 \pm 1.73$ & $2.02 \pm 1.46$ \\
\hline 22 & Heptanal & 901 & Aldehyde & $3.77 \pm 2.42$ & $-0.93 \pm 1.01$ & $1.00 \pm 1.71$ \\
\hline 23 & Hexadecanal & 1818.5 & Aldehyde & $0.01 \pm 0.13$ & $-1.19 \pm 2.68$ & $-1.85 \pm 1.02$ \\
\hline 24 & Tetradecanal & 1611.2 & Aldehyde & $1.73 \pm 0.47$ & $-1.41 \pm 0.67$ & $-0.60 \pm 1.70$ \\
\hline 25 & 2-Butanone & 576 & Ketone & $2.23 \pm 1.15$ & $-0.22 \pm 1.81$ & $-0.10 \pm 1.09$ \\
\hline 26 & 2-Nonanone & 1091.8 & Ketone & $2.27 \pm 0.52$ & $0.37 \pm 0.63$ & $0.83 \pm 0.58$ \\
\hline 27 & 3-Methyl-2-pentanone & 749.1 & Ketone & $2.54 \pm 1.25$ & $0.06 \pm 2.71$ & $-0.18 \pm 1.16$ \\
\hline 28 & 3-Pentanone & 700 & Ketone & $2.69 \pm 2.62$ & $4.91 \pm 0.89$ & $5.48 \pm 2.09$ \\
\hline 29 & Decanoic acid & 1369 & Fatty acid & $0.02 \pm 1.37$ & $-2.80 \pm 1.21$ & $-1.27 \pm 1.84$ \\
\hline 30 & $\gamma$-Valerolactone & 948.8 & Lactone & $-0.28 \pm 0.80$ & $-1.03 \pm 0.60$ & $0.14 \pm 0.88$ \\
\hline 31 & 2-Acetyl furan & 908.8 & Furan & $0.74 \pm 1.43$ & $0.09 \pm 1.56$ & $0.99 \pm 1.12$ \\
\hline 32 & Indane & 1031 & Indane & $-1.76 \pm 2.05$ & $-1.53 \pm 1.30$ & $-2.63 \pm 1.06$ \\
\hline
\end{tabular}

GLV, green leaf volatiles.

*Linear retention index for $\mathrm{rtx}-5 \mathrm{~ms}$ column.

${ }^{\dagger}$ Carene isomer or pseudolimonene.

*Tentative. 
application of $500 \mu \mathrm{g}$ JA ( $\mathrm{pH}$ 3.7; Sigma, St Louis, IL, USA) or received a mock treatment with acidic water on the fourth leaf from the apex of the plant (Supplementary information). Local and systemic leaves from the control plants as well as the herbivore- and JA-treated plants were harvested as separate sets at 6, 20, 24, 48 and $72 \mathrm{~h}$ after induction. Leaves from three plants were pooled together to obtain one sample, and three replicate pools were collected for each time point.

Gene expression of several enzymes involved in volatile synthesis and hormonal pathways controlling induced responses were analysed by RT-qPCR. The expression of three GLV biosynthesis genes, viz. hydroperoxide lyase1 (HPL1; Matsui et al. 1999; Matsui 2006), Chloroplastic Aldehyde Reductase (ChlADR; Yamauchi et al. 2011) and acetyl CoA:(Z)-3-hexen-1-ol acetyltransferase (CHAT; D'Auria et al. 2007), was measured. For the terpenoids biosynthetic pathway, gene expression of TPS10 (Bohlmann et al. 2000), TPS21 (Tholl et al. 2005) and CYP82G1 (Lee et al. 2010), which are involved in the synthesis of mono-, sesqui- and homoterpenes respectively, were examined. For the glucosinolatederived volatiles, expression of genes involved in the synthesis of aliphatic (CYP79F1 and CYP83A1; Bak \& Feyereisen 2001; Chen et al. 2003; Naur et al. 2003) and indole glucosinolates (CYP79B2; Glawischnig et al. 2004) was measured. Additionally, the expression of thiol methyltransferase1 (TMT1), a gene involved in the biosynthesis of sulphur volatiles (Attieh et al. 2002), was analysed. To investigate the hormonal pathways involved, the expression of marker genes for the JA pathway (MYC2 and VSP2; Berger et al. 2002; Lorenzo et al. 2004; Dombrecht et al. 2007), the SA pathway
(PR1; Bowling et al. 1997) and the ethylene pathway (ETR1 and ERF1; Lorenzo et al. 2003, 2004) was measured.

For primer design, orthologous sequences of the respective Arabidopsis thaliana gene were collected from all Brassica spp. sequences available in GenBank. Primers were designed on conserved stretches within the Brassica orthologous sequences, whereby cross-reactivity with paralogous Brassica sequences was avoided (Table 2). For each sample, $0.5 \mu \mathrm{g}$ of total RNA was reverse-transcribed into cDNA with the iScript cDNA Synthesis Kit (Bio-Rad Laboratories Inc., California, USA) according to the manufacturer's instructions. For each RNA sample, a negative control cDNA reaction was made by omitting the reverse transcriptase to verify that no samples were significantly contaminated with genomic DNA. Subsequently, all samples were diluted 20-fold with water. For each cDNA sample, qPCR amplification reactions were performed in triplicate.

The qPCR amplification mix was: $5 \mu \mathrm{L}$ diluted 1st strand cDNA, $0.75 \mu \mathrm{L}$ forward primer $(10 \mu \mathrm{M}), 0.75 \mu \mathrm{L}$ reverse primer $(10 \mu \mathrm{M}), 12.5 \mu \mathrm{L} \mathrm{iQ}^{\mathrm{TM}}$ SYBR Green Supermix (Bio-Rad Laboratories Inc., CA, USA) and $6 \mu \mathrm{L}$ $\mathrm{H}_{2} \mathrm{O}$. The qPCR was performed on the MyIQ SingleColor Real-Time PCR Detection System (Bio-Rad Laboratories Inc., CA, USA) according to the following protocol: an initial denaturation for $5 \mathrm{~min}$ at $95^{\circ} \mathrm{C}$, followed by 45 cycles of $15 \mathrm{~s}$ at $95{ }^{\circ} \mathrm{C}, 15 \mathrm{~s}$ at $58{ }^{\circ} \mathrm{C}$ and $15 \mathrm{~s}$ at $72{ }^{\circ} \mathrm{C}$. Thereafter, a melting curve analysis was performed to verify that only a single gene transcript had been amplified. To verify that primers were targeting the right gene, amplification fragments were cloned and sequenced.

Table 2 Primers sequences for gene expression analysis

\begin{tabular}{|c|c|c|c|}
\hline Gene & Arabidopsis thatiana locus & Forward Primer & Reverse Primer \\
\hline GAPC2 & AT1G13440 & 5'-AGTTGTTGACCTCACGGTTAGAC-3' & 5'-TTCCTCCTTGATAGCCTTCTTG-3' \\
\hline$P P 2 A$ & AT1G13320 & 5'-CATGCTCCAAGCTCTTACCTG-3' & 5'-AATTTGATGTTTGGAACTCTGTCTT-3' \\
\hline MYC2 & AT1G32640 & 5'-AGGTTGATGTCGGCGTTG-3' & 5'-CGTTAACCACCGACATACTCG-3' \\
\hline VSP2 & AT5G24770 & 5'-ATCTCGAAGCTGCTGGTTTC-3' & 5'-TTTGTGTTCGAACCCGTTG-3' \\
\hline ERF1 & AT3G23240 & 5'-CGGCGGAGAGAGTTAAAGAG-3' & 5'-AACACCCATCCTCGTAGCTG-3' \\
\hline ETR1 & AT1G66340 & 5'-CACCAAAGGCCACTGCTC-3' & 5'-GTGGATTTGTCGGTGTTACCAG-3' \\
\hline PR1 & AT2G14610 & 5'-CTACGCCGACCGACTAAGAG-3' & 5'-CTACTCCCGGCCAAGTTCTC-3' \\
\hline HPL1 & AT4G15440 & 5'-TGGTGATGAGAGACGCTAACA-3' & 5'-CCGATCCGGTTTAAATTCCT-3' \\
\hline ChlADR & AT1G54870 & 5'-CCTGGCTTGTAACCATTGCT-3' & 5'-CACCTCCGTTAGGGTGAAGA \\
\hline CHAT & AT3G03480 & 5'-TGTACGGTGGAACCGCTAAG-3' & 5'-GGCACGTAGAAGCTCACTCCT-3' \\
\hline TPS10 & AT2G24210 & 5'-AACTCTTTACTGCCGCCTTTG-3' & 5'-ACTCGGGGAGTTCATCGAGAC-3' \\
\hline TPS21 & AT5G23960 & 5'-GAGCACATTGTCTCTTTGCTCA-3' & 5'-AATCTCCACCAGTCCACCAC-3' \\
\hline CYP82G1 & AT3G25180 & 5'-TGTGGACATGTACGCGATG-3' & 5'-GGTGATGGATGTGCTGTCTG-3' \\
\hline CYP79B2 & AT4G39950 & 5'-AAGAGGTTGTGCTGCTCCG-3' & 5'-TCCAAGTGAAACCTTGAAGAAGTC-3' \\
\hline CYP79F1 & AT1G16410 & 5'-TTGGAACATTGATGGTCAAGAG-3' & 5'-TCTCGTCAATGATCGGATTG-3' \\
\hline CYP83A1 & AT4G13770 & 5'-СТССTTATCCCTCGTGCTTG-3' & 5'-TGTCGTAACCAGCGATCTTG-3' \\
\hline TMT1 & AT2G43920 & 5'-CGCCACTCGTAAGGGTAAAG-3' & 5'-TGGATCAGTTGATCTTCTTCCA-3' \\
\hline
\end{tabular}


Out of several potential reference genes tested, two most stable, GAPC2 and PP2A, were selected with the geNorm software (http://medgen.ugent.be/genorm/), and the relative expression levels of the target genes were calculated by normalization with the expression of the two reference genes (Vandesompele et al. 2002). Primer pair amplification efficiencies were determined with LinRegPCR software (Ruijter et al. 2009). Fold changes in gene expression levels were calculated by dividing the mean normalized expression of damaged plants group by the mean normalized expression of the undamaged plants group (Muller et al. 2002).

\section{Statistical analyses}

Insect preference was analysed using nonparametric replicated goodness of fit test with the null hypothesis of no preference (Sokal \& Rohlf 1995). Females that did not make a choice were excluded from the analysis.

For volatile analysis, we constructed a separate model for each day of volatile sampling and compared the profiles of the damaged plants collected on that day to control plants of the same day. Orthogonal partial least squares-discriminant analysis (OPLS-DA) method was applied to these models (Bylesjo et al. 2006): the resulting weight vector values reflect the volatile blend emitted from damaged plants compared with that of untreated control plants on each day. The $P$-values were determined using a permutation test. Models based on randomly permuted class labels (treatment groups) and of identical complexity were evaluated for their classification potential compared to the null hypothesis of no response.

Data of individual volatiles and their gene expression were statistically analysed by independent-sample $t$-test assuming unequal variances following the procedure in Rieu \& Powers (2009) using SPSS 17.0 (SPSS, Chicago, IL, USA).

\section{Results}

\section{Insect preference}

When offered a choice between undamaged plants and plants damaged for 24, 48 or $72 \mathrm{~h}$, the generalist herbivore Spodoptera litura significantly preferred undamaged plants (Fig. 2a, replicated G-test, $P<0.01$ ). Its parasitoid Cotesia marginiventris, however, favoured plants damaged for $48 \mathrm{~h}$ (Fig. 2c, replicated G-test, $P<0.001$ ). In contrast, the specialist herbivore Plutella xylostella
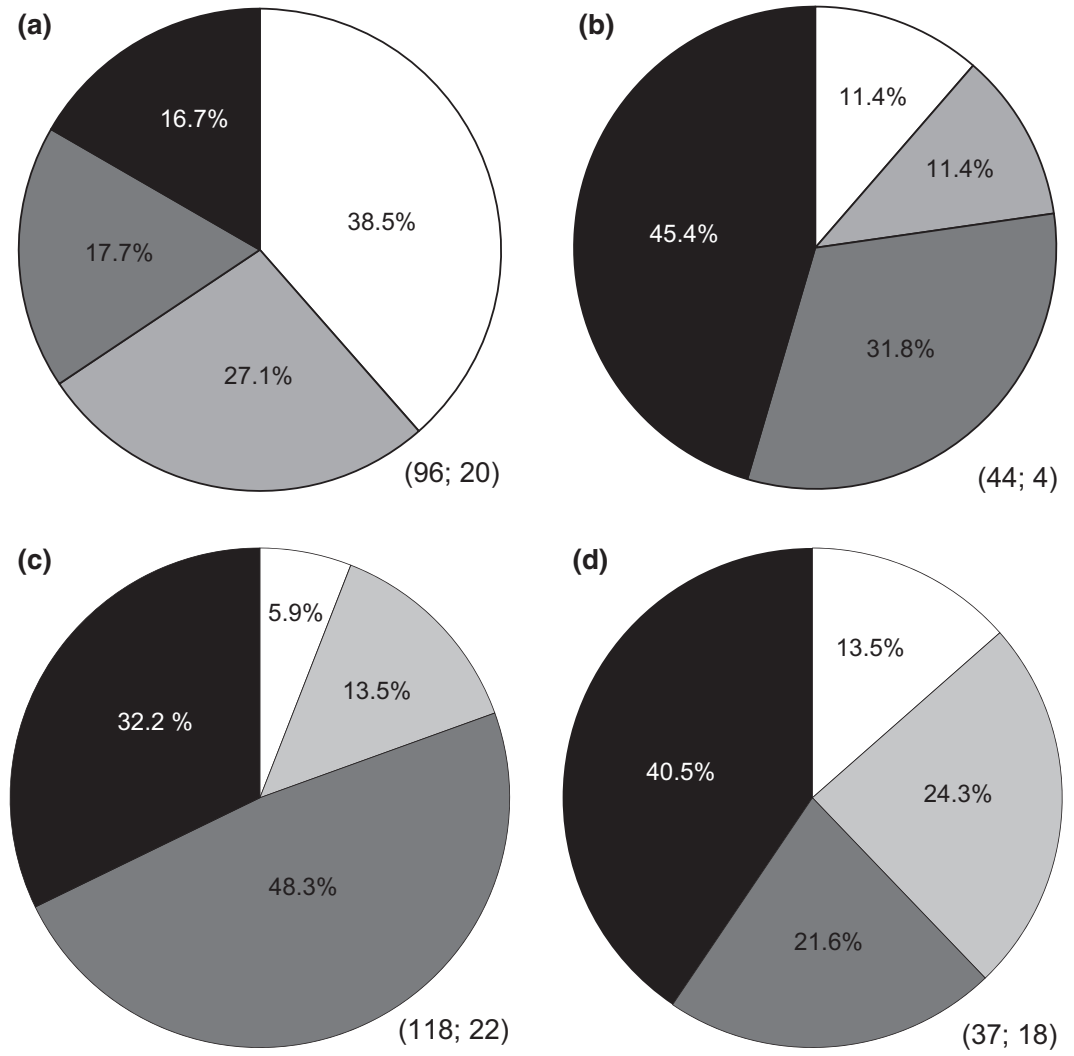

$\square$ Undamaged plants
Fig. 2 Orientation response of naive adult females of (a) Spodoptera litura $(n=96)$, (b) Plutella xylostella $(n=44),(\mathrm{c})$ Cotesia marginiventris $(n=118),(\mathrm{d})$ C. vestalis $(n=37)$ when undamaged plants and plants damaged for 24,48 or $72 \mathrm{~h}$ were offered as choice. The data were analysed using replicated G test goodness of fit and were found significant between treatments for (a; $P<0.01)$, (b; $P<0.005)$, (c; $P<0.001)$ and (d; $P<$ $0.05)$. The pie charts represent only the percentage of females that made a choice. Numbers in parentheses represent the number of females that made a choice and females that did not make a choice and were excluded during the experiment, respectively. 
(Fig. 2b; replicated G-test, $P<0.005$ ) and its parasitoid C. vestalis (Fig. $2 \mathrm{~d}$; replicated G-test, $P<0.05$ ) both preferred plants damaged for $72 \mathrm{~h}$ as compared to undamaged plants or plants damaged for 24 and $48 \mathrm{~h}$.

\section{Volatile analysis}

The volatile blends consisted of compounds of various classes including an isothiocyanate, GLVs, a salicylic acid ester, sulphides and terpenes along with other (unidentified) acids, ketones and aldehydes (Table 1). For each of the three time points, fold changes in the emission rates of individual compounds after S. exigua feeding compared with control values were calculated, and the complete blends were fitted in an OPLS-DA model, comparing the blends over three sampling days. The overall volatile blends of damaged plants were significantly different between days (Permutation test of the weight vector value; $P<0.01$ ). The three discriminant axes represent the contrast between the fold changes of plants damaged for 24, 48 and $72 \mathrm{~h}$ (Fig. 3a-c). The importance of each VOC in each contrast is represented by its position according to its weight vector value on each axis. Increased levels of a compound after 24,48 or $72 \mathrm{~h}$ damage are indicated by a positive weight vector value, and reduced levels are shown by a negative value on the respective axis.

The only isothiocyanate emitted, 1-butene-4-isothiocyanate, was strongly induced at $24 \mathrm{~h}$ after damage and remained at higher levels throughout the entire study period (independent-sample $t$-test, $P<0.01$ at $24 \mathrm{~h}$ and $P<0.005$ at $72 \mathrm{~h}$; compound 1 in Fig. $3 \mathrm{a}-\mathrm{c})$. The emission of GLV compounds, viz. 3-hexen-1-ol (compound 11; $P<0.05$ at 24 and $48 \mathrm{~h}$ ) and 3-hexen-1-ol-acetate (compound 12; $P<0.05$ at 24 and $72 \mathrm{~h}$ ), was also significantly increased following herbivory (Fig. 3a-c). We also observed a short burst in the emission of acetaldehyde (compound 13$)$ at $48 \mathrm{~h}(P<0.05$; Fig. 3a, c). In addition, acetic acid hexyl ester (compound 15) emissions showed a marginally significant increase at $72 \mathrm{~h}$ of damage only ( $P=0.058$; Fig. $3 b, c)$. The levels of acetic acid ethyl ester (compound 14) and hexadecanoic acid methyl ester (compound 16) showed no significant change in emission following herbivory (Table 1).

Among terpenes, which constituted the largest number of known compounds in the B. juncea volatile blend, the homoterpenes were the most prominently induced. Both homoterpenes, viz. (E,E)-4,8,12-trimethyl-1,3,7, 11-tridecatetraene (TMTT; compound 9) and $<3 \mathrm{E}>-4$, 8-dimethyl-1,3,7-nonatriene (DMNT; compound 10), were only emitted from damaged plants within $24 \mathrm{~h}$ of damage and emitted at higher rates, but inconsistently so, throughout the study period (Fig. $3 \mathrm{a}-\mathrm{C}$ ). The emission of DMNT was found to be significantly elevated at $72 \mathrm{~h}$ of damage $(P<0.05)$, but TMTT did not show significantly increased emissions at any time point tested due to the large variation between replicates (Table 1). We did not find any major changes in monoand sesquiterpene emissions (Table 1).

Both the sulphides detected, viz. dimethyldisulphide (DMDS) and dimethyltrisulphide (DMTS; compound 17 and 18, respectively), increased significantly over control levels at $72 \mathrm{~h}$ of damage $(P<0.05$; Table 1, Fig. 3b, c). The emission of salicylic acid hexyl ester (compound 19) showed a decreasing trend after $72 \mathrm{~h}$ of damage (Fig. 3b, c).

In addition, several other compounds were significantly affected by S. exigua feeding at different time points of the study. Among these, the most prominent compounds were 1-tetradecanol (compound 21; $P<0.05$ ) and 3-methyl-2-pentanone (compound 27, ketone; $p<0.05$ ) that increased at $24 \mathrm{~h}$ of damage, as well as 3-pentanone (compound 28, ketone; $p<0.01$ ) that increased at $48 \mathrm{~h}$ of damage (Fig. $3 \mathrm{a}-\mathrm{c}$ ). Other than the volatiles mentioned above, the OPLS-DA model shows several compounds belonging to various classes, such as alcohols, aldehydes and ketones that were different at various time points (e.g. compounds 26, 31, 32). However, the differences in their emission rates were not statistically significant due to high variation among the biological replicates (e.g. compound 9 at $24 \mathrm{~h}$ and compound 11 at $72 \mathrm{~h}$ in Table 1).

\section{Gene expression analysis}

Changes in the expression levels of all the tested genes were essentially stronger in damaged (local) leaves than in systemic leaves. In the local leaves, we observed a significant induction of MYC2 starting at $20 \mathrm{~h}$ after $S$. exigua damage (independent-sample $t$-test, $P<0.05$, Fig. 4a). VSP2 was repressed at 6 and 48 h, but induced at $20 \mathrm{~h}$ (Fig. 4b). In systemic leaves, no response was found for MYC2, while VSP2 was significantly induced almost twofold at time points 6 and $20 \mathrm{~h}$, but was also significantly repressed at $48 \mathrm{~h}$ (independent-sample t-test, $p<0.05)$. PR1, ETR1 and ERF1 principally did not show significant changes in their expression levels in either local or systemic leaves, except for a significant repression of PR1 at $72 \mathrm{~h}$ in systemic leaves (Fig. 4c-e). Similar gene expression patterns were found when we artificially induced plants using JA (Supporting information). We found that MYC2 and VSP2 were strongly induced in both local and systemic leaves, whereas no response was observed for PR1, ETR1 and ERF1 in the local as well as the systemic leaves (Fig. S2, Supporting information).

Temporal changes in the genes involved in GLV synthesis were quite pronounced, as was also observed in 

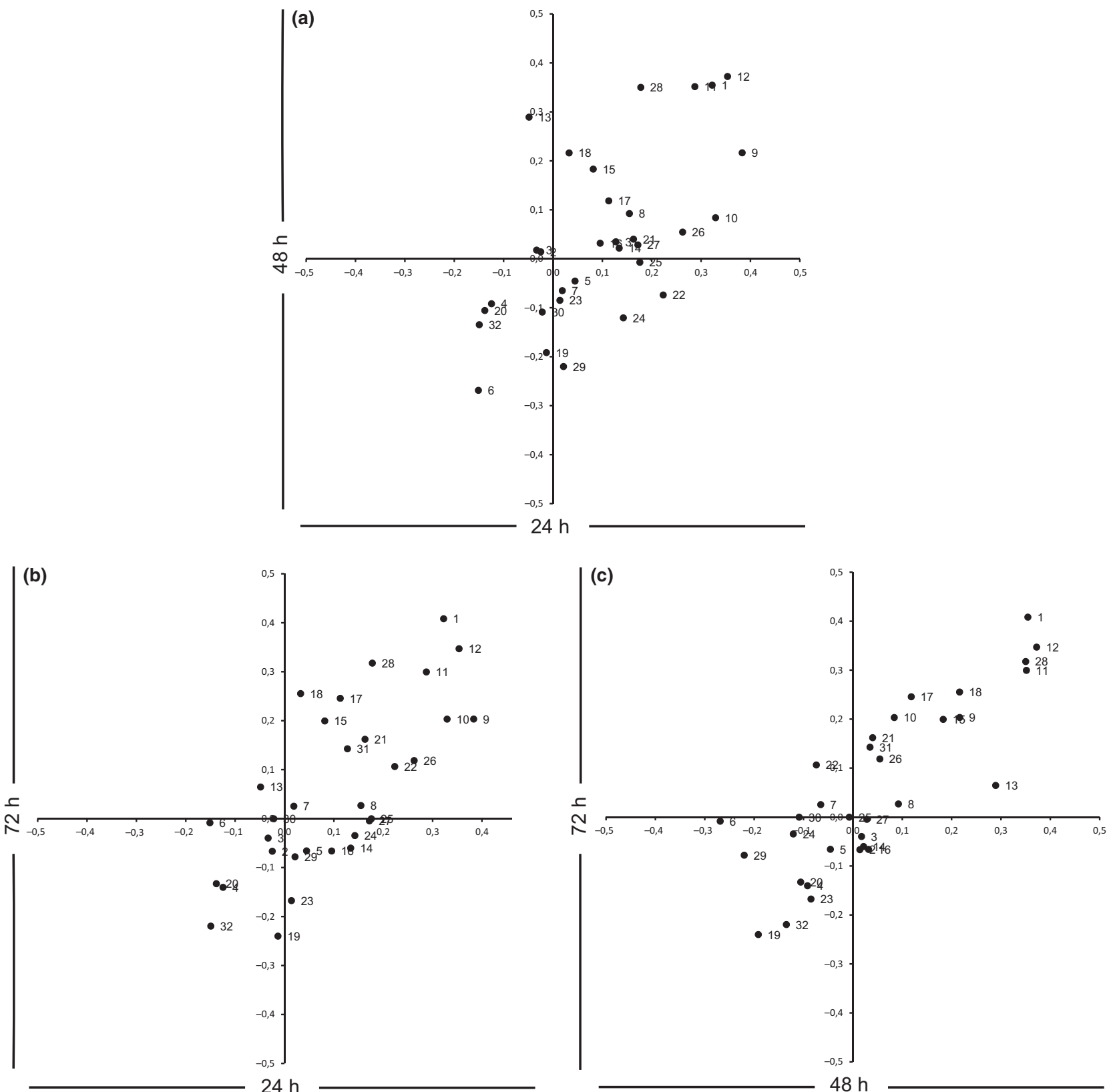

Fig. 3 Two-dimensional OPLS-Discriminant plots for VOCs emitted by Brassica juncea plants due to damage by Spodoptera exigua larvae, represented as discriminant functions of damage for 24,48 and $72 \mathrm{~h}$ plotted against each other. The two-dimensional plots show the contribution of each VOC for each treatment group on the $x$ or the $y$ axis: (a) $24 \mathrm{~h}$ vs. $48 \mathrm{~h}$, (b) $24 \mathrm{~h}$ vs. $72 \mathrm{~h}$ and (c) $48 \mathrm{~h}$ vs. $72 \mathrm{~h}$ of damage. Numbers correspond to compounds listed in Table 1. The position of each point is determined by its weight vector value in the VOC blend of each treatment group plotted.

the volatile analysis. HPL1 was significantly induced in the local leaves at time points 20, 24 and $48 \mathrm{~h}$, while in systemic leaves this induction was delayed until $72 \mathrm{~h}$ after damage (independent-sample $t$-test, $P<0.05$, Fig. 5a). In contrast, ChlADR was significantly repressed after $48 \mathrm{~h}$ of damage in the local leaves. In the systemic leaves, there was an increasing trend after $24 \mathrm{~h}$ followed by a decrease after $48 \mathrm{~h}$ of damage (Fig. 5b).
CHAT expression showed a trend for increase following herbivory in the local leaves. However, no significant induction or repression was observed in either local or systemic leaves at any of the analysed time points (Fig. 5c). The expression of genes involved in mono(TPS10) and sesquiterpene (TPS21) biosynthesis showed a large biological variation (Fig. 5d, e). Following herbivory, both TPS10 and TPS21 were slightly induced in 

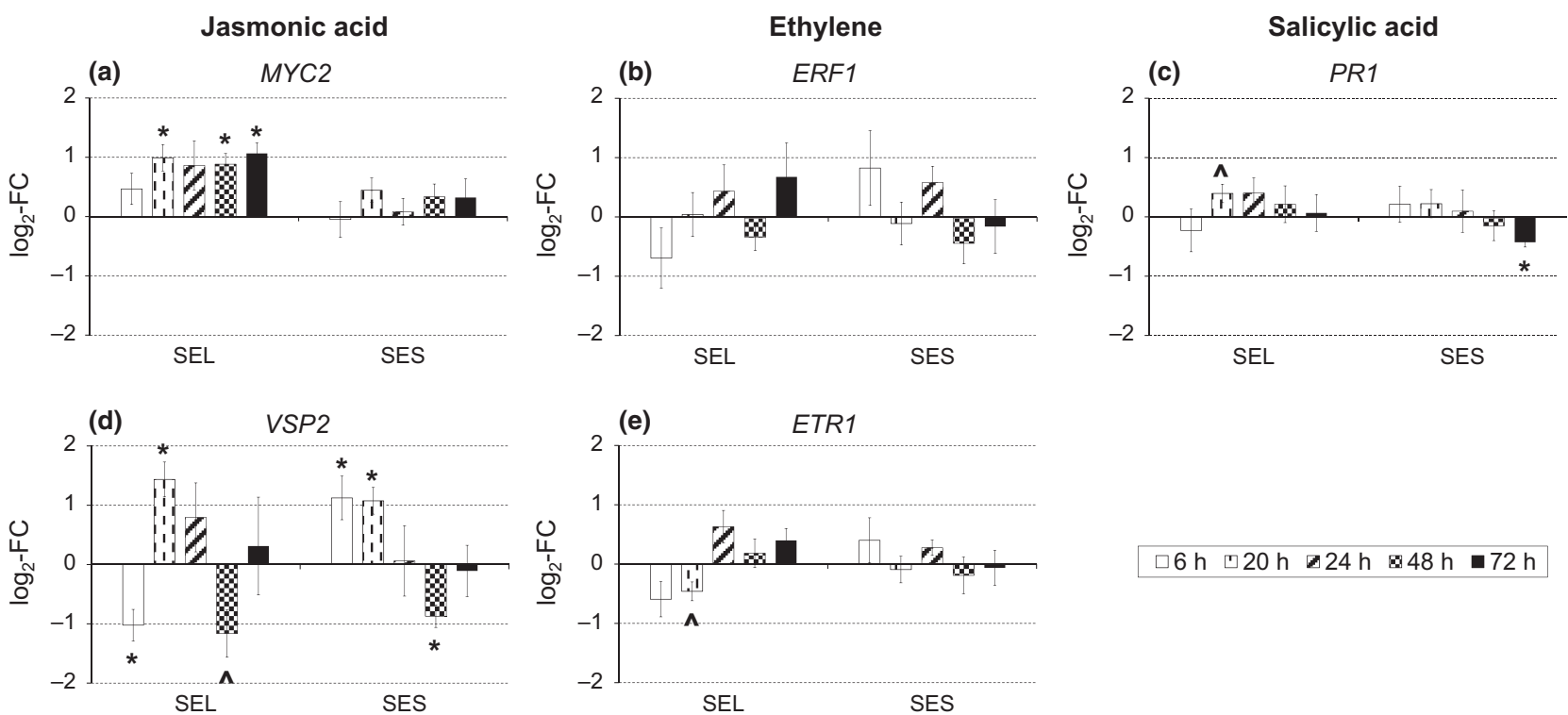

$\square 6 \mathrm{~h} \square 20 \mathrm{~h} \square 24 \mathrm{~h} \quad 48 \mathrm{~h} \square 72 \mathrm{~h}$

Fig. 4 RT-qPCR on marker genes for hormonal pathways. Relative fold changes in mean normalized expression at different time points of treatment vs. control for genes of the jasmonic acid, salicylic acid and ethylene hormonal pathways. SEL, local leaf after Spodoptera exigua induction; SES, systemic leaf after S. exigua induction. Error bars represent standard errors; statistically significant fold changes between control and treatment are marked by: ${ }^{\prime}, P<0.1 ; *, P<0.05$ ( $t$-test assuming unequal variances).
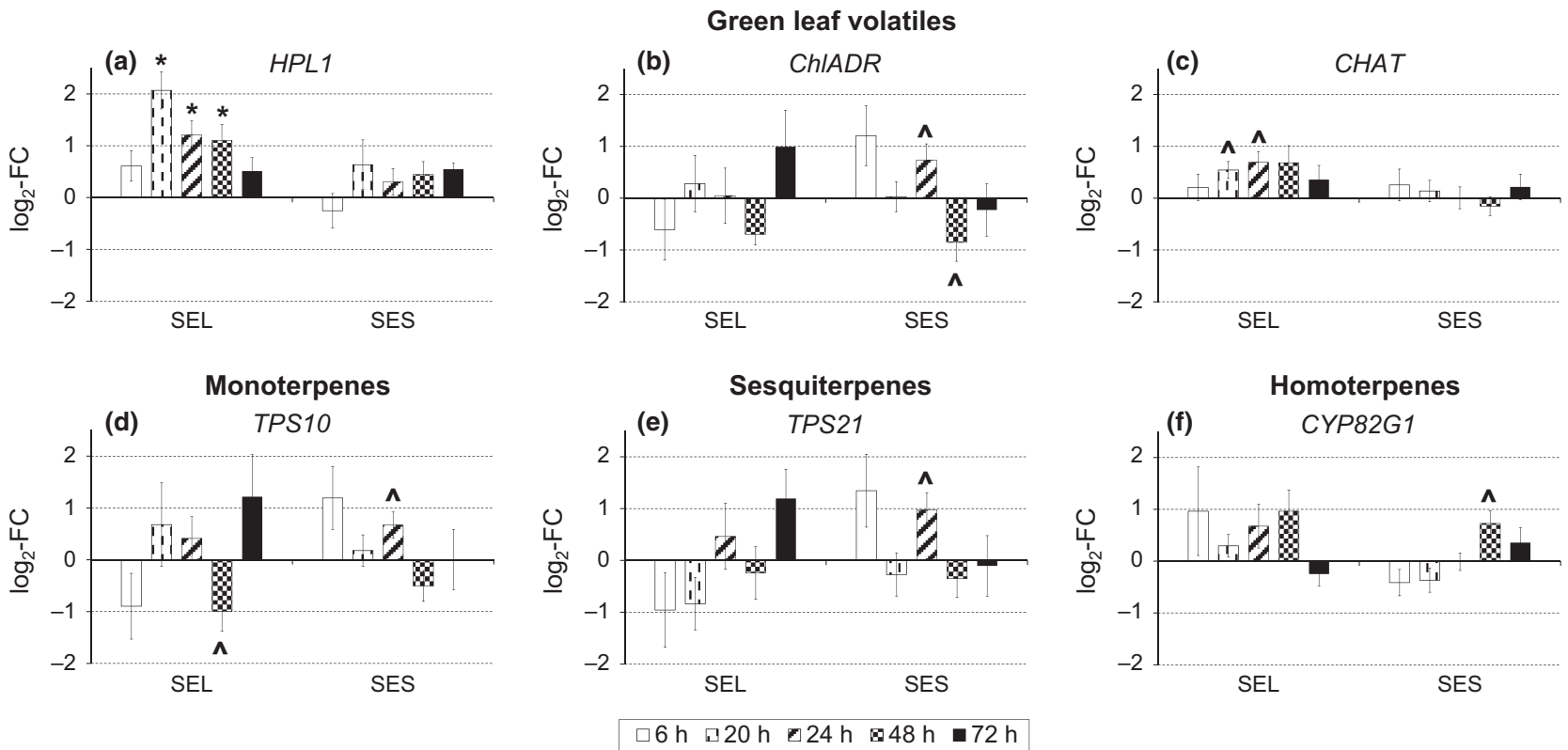

Fig. 5 RT-qPCR on volatile biosynthetic genes. Changes in gene expression levels are shown as relative fold changes in mean normalized expression at different time points of treatment vs. control. SEL, local leaf after Spodoptera exigua induction; SES, systemic leaf after S. exigua induction. Error bars represent standard errors; statistically significant fold changes between control and treatment are marked by: ${ }^{\wedge}, P<0.1 ; *, P<0.05$ (t-test assuming unequal variances).

the local leaves at $72 \mathrm{~h}$. In systemic leaves, these genes tended to increase at $24 \mathrm{~h}$. The gene CYP82G1, which is involved in homoterpene synthesis, had an increasing trend in local leaves following herbivory (Fig. 5f). Plants induced with JA also showed similar patterns for these genes, but the expressions of HPL1, CHAT and CYP82G1 were more pronounced than in the herbivore-damaged plants, possibly because the application of excess JA provides a stronger induction signal than herbivore feeding (Fig. S3, Supporting information).

CYP79F1 and CYP83A1 are involved in the synthesis of the aliphatic glucosinolates that are the precursors of 
1-butene-4-isothiocyanate (compound 1, Table 1). They showed a comparable induction pattern in response to herbivory (Fig. 6a, b). Both genes were significantly up-regulated at $72 \mathrm{~h}$ of damage in local leaves (independent-sample $t$-test; $P<0.05$ for CYP79F1; $P<0.1$ for CYP83A1). In systemic leaves, CYP79F1 was repressed at $20 \mathrm{~h}(P<0.1)$ and induced at $24 \mathrm{~h}(P<0.05)$. In contrast, no significant response due to herbivory was observed for CYP79B2, which is involved in the production of indole glucosinolates (Fig. 6c). The expression of TMT1, involved in the synthesis of sulphides, showed a marked induction in local leaves at 20, 24 and $72 \mathrm{~h}$ after damage (independent-sample $t$-test, $P<0.05$ ). The expression pattern of TMT1 showed a similar trend in systemic leaves (Fig. 6d). In JA-induced plants, a largely similar response for the glucosinolate biosynthesis genes and TMT1 was observed (Fig. S4, Supporting information).

\section{Discussion}

In this study, we associated the preference of generalist and specialist herbivores and their parasitoids to the temporal dynamics of HIPV emissions and corresponding changes in their gene expression in Brassica juncea. We found that the generalist Spodoptera litura was most attracted to undamaged plants, whereas the specialist Plutella xylostella preferred plants that were damaged for $72 \mathrm{~h}$. The parasitoids of both of these herbivores were attracted to damaged plants. However, Cotesia marginiventris, the parasitoid of S. litura, preferred plants damaged for $48 \mathrm{~h}$, whereas C. vestalis, corresponding to the preference of its host P. xylostella, preferred plants damaged for $72 \mathrm{~h}$. A clear difference was found in the composition of volatile blends between damaged and control plants as well as between the induced plants measured at three time points $(24,48$ or $72 \mathrm{~h}$ ) following herbivory. OPLS-DA revealed that a few specific compounds characterized the odour blend of the induced plants at each time point. Prominent volatiles in the HIPV blends of B. juncea were 1-butene-4-isothiocyanate, several GLVs and ketones that increased, as well as the homoterpenes TMTT and DMNT that were emitted at higher levels following herbivory. Additionally, there was a conspicuous increase in sulphides at $72 \mathrm{~h}$ and decrease in the monoterpene $\beta$-ocimene, salicylic acid hexyl ester and decanoic acid at $48 \mathrm{~h}$. HIPV emissions thus did not simply increase with time or amount of damage, but individual compounds within the blend showed specific temporal dynamics to which the herbivores and parasitoids may have responded. Gene expression patterns largely mirrored the observed temporal dynamics of the different volatile emissions, indicating that these volatiles were mainly newly synthesized and that the formation of these volatiles is an active and well-regulated process in the plants.

Following herbivory, we found that 1-butene-4-isothiocyanate increased consistently with time after damage. The emission of 1-butene-4-isothiocyanate results from the myrosinase-catalysed conversion of 3-butenyl glucosinolate (gluconapin), the main glucosinolate in
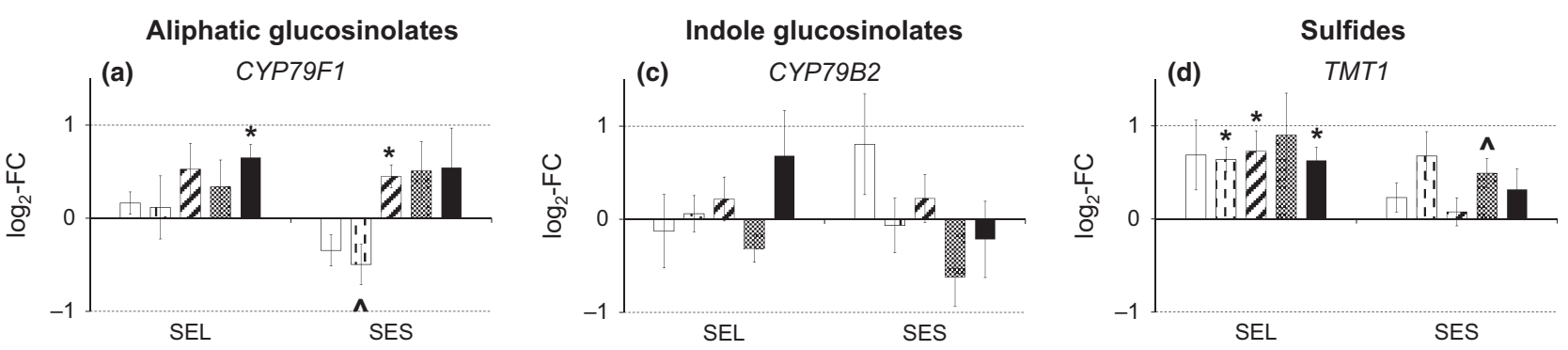

(b)

CYP83A1

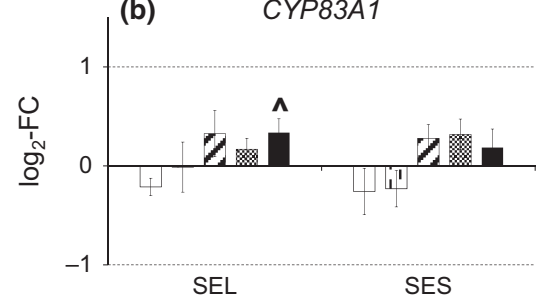

$\square 6 \mathrm{~h} \square 20 \mathrm{~h} \quad 224 \mathrm{~h} \quad 48 \mathrm{~h} \quad 72 \mathrm{~h}$

Fig. 6 RT-qPCR on sulphur-containing volatile biosynthetic genes. Changes in gene expression levels are shown as relative fold changes in mean normalized expression at different time points of treatment vs. control. SEL, local leaf after Spodoptera exigua induction; SES, systemic leaf after S. exigua induction. Error bars represent standard errors; statistically significant fold changes between control and treatment are marked by: $\wedge, P<0.1 ; *, P<0.05$ ( $t$-test assuming unequal variances). 
B. juncea leaves (Mathur et al. 2011, 2013). A previous study showed that herbivory increased leaf concentrations of gluconapin within 4 days after damage by Spodoptera spp. (Mathur et al. 2011). Indeed, we found that expression of alkenyl glucosinolate biosynthesis genes is induced within the same time frame, thereby fuelling the induction of both direct (glucosinolates) and indirect (break-down products) compounds.

Both herbivores and their natural enemies responded to damage-induced variation in the concentration of glucosinolate breakdown products as cues to localize their hosts. Our results are in line with the previous studies that show that their preference to induced volatiles differs with the degree of their specialization (Mumm et al. 2008a; Gols \& Harvey 2009; Pierre et al. 2011). As expected, the generalist herbivore S. litura preferred undamaged plants, on which the performance of its offspring will be better, than damaged plants (Mathur et al. 2011). These studies are consistent with earlier studies demonstrating that the same HIPVs that attract specialist herbivores and parasitoids can repel generalist herbivores (De Moraes et al. 2001; Karban \& Baxter 2001). Plutella xylostella, on the other hand, preferred plants damaged for $72 \mathrm{~h}$, for which 1-butene-4-isothiocyanate emissions were found to be the highest. Earlier studies revealed that increased levels of isothiocyanates are highly attractive to P. xylostella (Pivnick et al. 1994). This suggests that 1-butene-4-isothiocyanate plays an important role in the attraction of this specialist to B. juncea as well. The question is why P.xylostella would prefer to oviposit on previously damaged plants on which their offspring may be confronted with a number of challenges, including competition for available food, elevated plant defences and enhanced attraction of natural enemies such as predators and parasitoids. The induction of glucosinolates may not pose a threat to P. xylostella because it is known to 'disarm' these compounds in several plant species with a specific sulphatase that prohibits the formation of isothiocyanates (Ratzka et al. 2002). Earlier, Shiojiri et al. (2002) found that P.xylostella preferred plants already infested with Pieris rapae $\mathrm{L}$. over uninfested plants and that parasitism of P. xylostella by its parasitoid C. vestalis was lower when the plant was doubly infested than when it was infested by P. xylostella alone. Thus, the production of 'signal noise' by other herbivore species may represent a form of enemy-free space for the herbivore, and its preference for plants infested by other species of herbivores might be an adaptation to reduce the chances of being parasitized (Hare 2011).

Our results also showed, however, that the preference of P. xylostella for damaged B. juncea plants does not necessarily provide enemy free space, because its parasitoid, C. vestalis was also most attracted to the same plants. Likely, C. vestalis uses the isothiocyanate as a cue as well, but we also observed that the emission of two other sulphur-containing compounds, viz. DMDS and DMTS, was the highest at $72 \mathrm{~h}$ of damage. Earlier studies by Reddy et al. (2002) have established that C. vestalis is attracted to these sulphides. Changes in the emissions of sulphides after shoot or root herbivore damage in Brassica species have been described before (Geervliet et al. 1998; Crespo et al. 2012; van Dam et al. 2012). Thus, elevated emissions of DMDS were found to be correlated with the deterrence of a specialist parasitoid (Soler et al. 2007). Our observation that C. vestalis females were attracted to plants damaged for $72 \mathrm{~h}$, which also emitted the highest levels of sulphides, underscores the possible role of these HIPVs in attracting these specialized natural enemies to damaged plants. Moreover, the fact that TMT1, the gene responsible for the synthesis of DMDS and DMTS, was induced after S. exigua larval feeding, shows that the emission of sulphides is actively regulated by the plant. Earlier, several thiol methyltransferases were described that methylate glucosinolate hydrolysis products formed by myrosinases (Attieh et al. 2000a,b, 2002), which are further oxidized to form volatile compounds such as DMDS and DMTS. Eventually, the sum of all positive and negative effects will determine whether the attraction of P. xylostella to damaged plants is an example that 'mother does not always know best' or whether long-term fitness gains may play a role in this seemingly counterintuitive result (Mayhew 2001). Further research in the field is necessary to fully understand the costs and benefits for P. xylostella in preferring infested over uninfested plants for oviposition.

Green leaf volatiles and terpenoids together comprise a large and diverse portion of the volatile blends emitted by some species of intact as well as damaged brassicaceous plants (van Poecke et al. 2001; Mumm et al. 2008b). In B. juncea, most of the GLV compounds increased within $24 \mathrm{~h}$ of herbivore damage, and the expression profile of two of the three genes associated with their production showed a similar pattern. In contrast, the emission of $\beta$-ocimene, a monoterpene, had decreased within $48 \mathrm{~h}$ of initial damage. In Arabidopsis thaliana, TPS10 is involved in the synthesis of this compound (Bohlmann et al. 2000) and the activity of this gene was indeed slightly repressed both in local and systemic leaves in damaged plants. Sesquiterpenes showed no reaction to damage either at the level of volatile emissions or at the level of gene expression. On the other hand, the two homoterpenes, viz., TMTT and DMNT, were produced de novo following herbivory. In other plants species, these compounds were also found to be newly produced or increased in quantity following damage or treatment with elicitors (Turlings et al. 
1990; van Poecke et al. 2001; Herde et al. 2008; Pierre et al. 2011). Homoterpenes serve as very specific and reliable cues for parasitoids (Mumm et al. 2008b) and thus may have contributed to the enhanced attraction of the parasitoids in our study.

Both GLVs (Mattiacci et al. 1994; Halitschke et al. 2008) and terpenes (Degenhardt et al. 2003; de Boer et al. 2004) are well known to attract natural enemies of herbivores. McCormick et al. (2012) describe three possible means of odour discrimination: (i) species-specific odour recognition, in which the carnivore separates plant volatile compounds restricted to a single species or group of related species of herbivores; (ii) ratio-specific odour recognition, whereby a ratio of compounds in the volatile blend is recognized; (iii) whole-blend odour recognition, in which the entire blend or many of its components are perceived as a whole. The ability of a parasitoid to distinguish between volatile blends depends on the dietary specialization of both parasitoid and its herbivore host (Vet \& Dicke 1992; Steidle \& van Loon 2003). Specialist parasitoids cannot rely solely on induced terpenoids and GLVs for the detection of their specific host, because these compounds are not specific to any particular herbivore damage and hence do not give a reliable cue of the presence of their host (Vet et al. 1991; van Dam et al. 2010; Gols et al. 2011). Conversely, generalist parasitoids that attack several herbivores feeding on plants of different families may rely on more generalized cues (Gols et al. 2012). Earlier studies have demonstrated that C. marginiventris takes cues from both terpenoids and GLVs for its host location (Turlings et al. 1991). Electro-antennogram recordings of C. marginiventris confirm their ability to detect GLVs (Chen \& Fadamiro 2007; Ngumbi et al. 2010). Based on our results, we speculate that this parasitoid uses changes in the amounts or ratios in terpenoids and GLVs after $48 \mathrm{~h}$ of damage as cues to locate their host, as they were most attracted to these plants.

To date, more than 25 species of natural enemies in the third trophic level are known to be attracted to HIPVs (Mumm \& Dicke 2010; Reddy 2012). However, the chemical diversity of HIPVs makes it difficult to establish which of the blend components may evoke innate responses in naïve parasitoids. In fact, studies aimed at identifying the minimal blend showed that some compounds in the complete blend may mask the attractive components (Turlings \& Fritzsche 1999). Therefore, the value of attraction is believed to be determined by the relative reliability and detectability of plant volatile signals (Vet et al. 1991). By showing different blends of volatiles at different time points, our study provides a fair explanation for the differential preference of the parasitoids and herbivores to these plants. Since we combine the behaviour of insect herbivores and their parasitoids with the dynamics of HIPV blend, we can infer the ecological importance of these dynamics. However, as the most important odour cue for the generalist parasitoids may be determined by specific ratios of the emitted volatiles within the blend, it is challenging to pinpoint which compounds are the most important (Gols \& Harvey 2009).

We also found that after the plants were subjected to S. exigua damage, MYC2 and VSP2 were both significantly induced indicating that this herbivore induced the JA pathway in B. juncea. In contrast, there were no significant changes in the expressions of genes involved in the SA or ET pathways; PR1 was even repressed by $72 \mathrm{~h}$ of damage. Moreover, the expression profiles of the hormonal pathway marker genes and the volatile biosynthesis genes were largely comparable in the herbivore-damaged and ectopically JA-induced plants. This clearly indicates that the responses induced by S. exigua feeding are mainly controlled by the JA pathway in B. juncea. Many herbivore-induced responses regulated by the JA pathway are coregulated by the ET and SA pathway (Dicke et al. 1999; Genoud \& Metraux 1999). For example, the JA and ET pathways converge in the transcriptional activation of ERF1, and hence increase in ERF1 expression would indicate a synergistic response of JA and ET pathways (Lorenzo et al. 2003). Moreover, components in S. exigua oral secretions can suppress the JA pathway by activating the SA pathway in N. attenuata (Diezel et al. 2009). In B. juncea, however, we did not find any significant activity in the ET pathway, whereas the SA pathway was found to be repressed.

Herbivore-induced plant volatiles have been studied extensively in plant-herbivore-carnivore systems in crops, and this has greatly enhanced our understanding of the mechanisms involved in their expression. There is ample evidence that carnivores selectively exploit damage-induced plant volatiles in Brassicaceae for locating their herbivorous hosts or prey in greenhouse and in agro-ecosystems (Geervliet et al. 1996; Bukovinszky et al. 2005; Poelman et al. 2009; van Dam et al. 2010). Here, we tested whether the temporal dynamics of HIPV emissions could influence the plant's interactions with herbivores and their enemies. We demonstrated that HIPVs allow herbivores as well as their parasitoids to discriminate between herbivoreinfested plants subjected to different time periods of damage. Furthermore, the responses of the insects are dependent on temporal variations in the emissions of volatiles after initial feeding damage to plant tissues. This temporal pattern is also reflected in the dynamics of the genes involved in the synthesis of the volatiles and their precursors. Our study thus provides a comprehensive analysis of the mechanisms underlying temporal patterns of HIPV emissions and their function in 
natural environments. We suggest further studies to understand the ecological implication of temporal dynamics of HIPVs under field conditions in which multitrophic interactions in agro- and natural ecosystems are compared. In particular, little is known about the accuracy of agricultural systems as proxies for natural systems in which the insects originally evolved (Gols \& Harvey 2009; Gols et al. 2011). Wild plants often possess traits, such as volatile blends, that are more attractive to natural enemies than cultivated plants which have undergone many generations of artificial selection to accentuate certain traits that may or may not be compatible with indirect defence (Gols \& Harvey 2009; Hare 2011). A better knowledge of insect responses in wild plants under natural selection can thus contribute to the development of better biological control practices through selective breeding and hence more sustainable agricultural practices for Brassica crops.

\section{Acknowledgements}

We thank Om Prakash Singh for plants and insect care in India, Dr. Patrick Kabouw for statistical advice, Rieta Gols and Dr. Jeske de Boer (WUR, Wageningen, NL) for experimental advices and providing $C$. vestalis females and $A b$ and Gillis Wijlhuizen and Gregor Disveld (NIOO-KNAW, NL) for their technical support. We are grateful to Dr. Matthias Erb (MPI-CE, Jena, Germany) for providing Cotesia marginiventris and Leon Westerd (WUR, Wageningen, NL) for providing S. exigua larvae. This research was funded by grants to Vartika Mathur from Nuffic (Netherlands Organization for International Cooperation in Higher Education) and UGC [(University Grants Commission; Grant No. 39-319/2010(SR)] in NL and India, respectively.

\section{References}

Adie B, Chico JM, Rubio-Somoza I, Solano R (2007) Modulation of plant defenses by ethylene. Journal of Plant Growth Regulation, 26, 160-177.

Arimura G, Kost C, Boland W (2005) Herbivore-induced, indirect plant defences. Biochimica et Biophysica Acta, 1734, 91-111.

Arimura G, Matsui K, Takabayashi J (2009) Chemical and molecular ecology of herbivore-induced plant volatiles: proximate factors and their ultimate functions. Plant and Cell Physiology, 50, 911-923.

Attieh J, Kleppinger-Sparace KF, Nunes C, Sparace SA, Saini HS (2000a) Evidence implicating a novel thiol methyltransferase in the detoxification of glucosinolate hydrolysis products in Brassica oleracea L. Plant, Cell \& Environment, 23, 165-174.

Attieh J, Sparace SA, Saini HS (2000b) Purification and properties of multiple isoforms of a novel thiol methyltransferase involved in the production of volatile sulfur compounds from Brassica oleracea. Archives of Biochemistry and Biophysics, 380, 257-266.

Attieh J, Djiana R, Koonjul P et al. (2002) Cloning and functional expression of two plant thiol methyltransferases: a new class of enzymes involved in the biosynthesis of sulfur volatiles. Plant Molecular Biology, 50, 511-521.

Bak S, Feyereisen R (2001) The involvement of two P450 enzymes, CYP83B1 and CYP83A1, in auxin homeostasis and glucosinolate biosynthesis. Plant Physiology, 127, 108-118.

Berger S, Mitchell-Olds T, Stotz HU (2002) Local and differential control of vegetative storage protein expression in response to herbivore damage in Arabidopsis thaliana. Physiologia Plantarum, 114, 85-91.

de Boer JG, Posthumus MA, Dicke M (2004) Identification of volatiles that are used in discrimination between plants infested with prey or nonprey herbivores by a predatory mite. Journal of Chemical Ecology, 30, 2215-2230.

de Boer JG, Hordijk CA, Posthumus MA, Dicke M (2008) Prey and non-prey arthropods sharing a host plant: effects on induced volatile emission and predator attraction. Journal of Chemical Ecology, 34, 281-290.

Bohlmann J, Martin D, Oldham NJ, Gershenzon J (2000) Terpenoid secondary metabolism in Arabidopsis thaliana: cDNA cloning, characterization, and functional expression of a myrcene/(E)-[beta]-ocimene synthase. Archives of Biochemistry and Biophysics, 375, 261-269.

Bowling SA, Clarke JD, Liu YD, Klessig DF, Dong XN (1997) The cpr5 mutant of Arabidopsis expresses both NPR1-dependent and NPR1-independent resistance. The Plant Cell, 9, 1573-1584.

Broekgaarden C, Poelman EH, Voorrips RE, Dicke M, Vosman B (2010) Intraspecific variation in herbivore community composition and transcriptional profiles in field-grown Brassica oleracea cultivars. Journal of Experimental Botany, 61, 807-819.

Bruinsma M, Posthumus MA, Mumm R et al. (2009) Jasmonic acid-induced volatiles of Brassica oleracea attract parasitoids: effects of time and dose, and comparison with induction by herbivores. Journal of Experimental Botany, 60, 2575-2587.

Bukovinszky T, Gols R, Posthumus MA, Vet LEM, van Lenteren JC (2005) Variation in plant volatiles and attraction of the parasitoid Diadegma semiclausum (Hellen). Journal of Chemical Ecology, 31, 461-480.

Bylesjo M, Rantalainen M, Cloarec O et al. (2006) OPLS discriminant analysis: combining the strengths of PLS-DA and SIMCA classification. Journal of Chemometrics, 20, 341-351.

Chen L, Fadamiro HY (2007) Differential electroantennogram response of females and males of two parasitoid species to host-related green leaf volatiles and inducible compounds. Bulletin of Entomological Research, 97, 515-522.

Chen SX, Glawischnig E, Jorgensen K et al. (2003) CYP79F1 and CYP79F2 have distinct functions in the biosynthesis of aliphatic glucosinolates in Arabidopsis. The Plant Journal, 33, 923-937.

Conti E, Zadra C, Salerno G et al. (2008) Changes in the volatile profile of Brassica oleracea due to feeding and oviposition by Murgantia histrionica (Heteroptera: Pentatomidae). European Journal of Entomology, 105, 839-847.

Crespo E, Hordijk CA, de Graaf RM et al. (2012) On-line detection of root-induced volatiles in Brassica nigra plants infested with Delia radicum L. root fly larvae. Phytochemistry, 84, 68-77.

van Dam NM (2009) How plants cope with biotic interactions. Plant Biology, 11, 1-5.

van Dam NM, Tytgat TOG, Kirkegaard JA (2009) Root and shoot glucosinolates: a comparison of their diversity, 
function and interactions in natural and managed ecosystems. Phytochemistry Reviews, 8, 171-186.

van Dam NM, Qiu BL, Hordijk CA, Vet LEM, Jansen JJ (2010) Identification of biologically relevant compounds in aboveground and belowground induced volatile blends. Journal of Chemical Ecology, 36, 1006-1016.

van Dam NM, Samudrala D, Harren FJ, Cristescu SM (2012) Real-time analysis of sulfur-containing volatiles in Brassica plants infested with root-feeding Delia radicum larvae using proton-transfer reaction mass spectrometry. AoB Plants, 2012, pls021.

D'Auria JC, Pichersky E, Schaub A, Hansel A, Gershenzon J (2007) Characterization of a BAHD acyltransferase responsible for producing the green leaf volatile (Z)-3-hexen1-yl acetate in Arabidopsis thaliana. The Plant Journal, 49, 194-207.

De Moraes CM, Lewis WJ, Pare PW, Alborn HT, Tumlinson JH (1998) Herbivore-infested plants selectively attract parasitoids. Nature, 393, 570-573.

De Moraes CM, Mescher MC, Tumlinson JH (2001) Caterpillarinduced nocturnal plant volatiles repel conspecific females. Nature, 410, 577-580.

De Vos M, Van Oosten VR, Van Poecke RMP et al. (2005) Signal signature and transcriptome changes of Arabidopsis during pathogen and insect attack. Molecular Plant-Microbe Interactions, 18, 923-937.

De Vos M, Van Oosten VR, Jander G, Dicke M, Pieterse CM (2007) Plants under attack: multiple interactions with insects and microbes. Plant Signaling \& Behavior, 2, 527-529.

Degenhardt J, Gershenzon J, Baldwin IT, Kessler A (2003) Attracting friends to feast on foes: engineering terpene emission to make crop plants more attractive to herbivore enemies. Current Opinion in Biotechnology, 14, 169-176.

Dicke M, Baldwin IT (2010) The evolutionary context for herbivore-induced plant volatiles: beyond the 'cry for help'. Trends in Plant Science, 15, 167-175.

Dicke M, Vet LEM (1999) Plant-carnivore interactions: evolutionary and ecological consequences for plant, herbivore and carnivore. In: Herbivores: Between Plants and Predators (eds Olff H., Brown V. K. \& Drent R. H.), pp. 483-520. Blackwell Science, London.

Dicke M, Gols R, Ludeking D, Posthumus MA (1999) Jasmonic acid and herbivory differentially induce carnivore-attracting plant volatiles in lima bean plants. Journal of Chemical Ecology, 25, 1907-1922.

Diezel C, von Dahl CC, Gaquerel E, Baldwin IT (2009) Different lepidopteran elicitors account for cross-talk in herbivoryinduced phytohormone signaling. Plant Physiology, 150, 1576-1586.

Dombrecht B, Xue GP, Sprague SJ et al. (2007) MYC2 differentially modulates diverse jasmonate-dependent functions in Arabidopsis. The Plant Cell, 19, 2225-2245.

Ehlting J, Chowrira SG, Mattheus N et al. (2008) Comparative transcriptome analysis of Arabidopsis thaliana infested by diamond back moth (Plutella xylostella) larvae reveals signatures of stress response, secondary metabolism, and signalling. BMC Genomics, 9, 154.

Erb M, Meldau S, Howe GA (2012) Role of phytohormones in insect-specific plant reactions. Trends in Plant Science, 17, 250-259.
Franzke A, Lysak MA, Al-Shehbaz IA, Koch MA, Mummenhoff K (2011) Cabbage family affairs: the evolutionary history of Brassicaceae. Trends in Plant Science, 16, 108-116.

Gatehouse JA (2002) Plant resistance towards insect herbivores: a dynamic interaction. New Phytologist, 156, 145-169.

Geervliet JBF, Vet LEM, Dicke M (1996) Innate responses of the parasitoids Cotesia glomerata and C. rubecula (Hymenoptera: Braconidae) to volatiles from different plant-herbivore complexes. Journal of Insect Behavior, 9, 525-538.

Geervliet JBF, Vreugdenhil AI, Dicke M, Vet LEM (1998) Learning to discriminate between infochemicals from different plant-host complexes by the parasitoids Cotesia glomerata and C. rubecula (Hym: Braconidae). Entomologia Experimentalis et Applicata, 86, 241-252.

Genoud T, Metraux JP (1999) Crosstalk in plant cell signaling: structure and function of the genetic network. Trends in Plant Science, 4, 503-507.

Glawischnig E, Hansen BG, Olsen CE, Halkier BA (2004) Camalexin is synthesized from indole-3-acetaldoxime, a key branching point between primary and secondary metabolism in Arabidopsis. Proceedings of the National Academy of Sciences of the United States of America, 101, 8245-8250.

Gols R, Harvey JA (2009) Plant-mediated effects in the Brassicaceae on the performance and behaviour of parasitoids. Phytochemistry Reviews, 8, 187-206.

Gols R, Bukovinszky T, van Dam NM et al. (2008) Performance of generalist and specialist herbivores and their endoparasitoids differs on cultivated and wild Brassica populations. Journal of Chemical Ecology, 34, 132-143.

Gols R, Bullock JM, Dicke M, Bukovinszky T, Harvey JA (2011) Smelling the wood from the trees: non-linear parasitoid responses to volatile attractants produced by wild and cultivated cabbage. Journal of Chemical Ecology, 37, 795-807.

Gols R, Veenemans C, Potting RPJ et al. (2012) Variation in the specificity of plant volatiles and their use by a specialist and a generalist parasitoid. Animal Behaviour, 83, 1231-1242.

Gosset V, Harmel N, Göbel C et al. (2009) Attacks by a piercing-sucking insect (Myzus persicae Sultzer) or a chewing insect (Leptinotarsa decemlineata Say) on potato plants (Solanum tuberosum L.) induce differential changes in volatile compound release and oxylipin synthesis. Journal of Experimental Botany, 60, 1231-1240.

Halitschke R, Baldwin IT (2003) Antisense LOX expression increases herbivore performance by decreasing defense responses and inhibiting growth-related transcriptional reorganization in Nicotiana attenuata. The Plant Journal, 36, 794-807.

Halitschke R, Stenberg JA, Kessler D, Kessler A, Baldwin IT (2008) Shared signals - 'alarm calls' from plants increase apparency to herbivores and their enemies in nature. Ecology Letters, 11, 24-34.

Hare JD (2011) Ecological role of volatiles produced by plants in response to damage by herbivorous insects. Annual Review of Entomology, 56, 161-180.

Herde M, Gartner K, Kollner TG et al. (2008) Identification and regulation of TPS04/GES, an Arabidopsis geranyllinalool synthase catalyzing the first step in the formation of the insect-induced volatile C-16-homoterpene TMTT. The Plant Cell, 20, 1152-1168.

Hoagland DR, Arnon DI (1950) The water culture method for growing plants without soil. Bulletin of the Californian Agricultural Experiment Station, 347, 1-32. 
Holopainen JK (2004) Multiple functions of inducible plant volatiles. Trends in Plant Science, 9, 529-533.

Hopkins RJ, van Dam NM, van Loon JJA (2009) Role of glucosinolates in insect-plant relationships and multitrophic interactions. Annual Review of Entomology, 54, 57.

Howe GA, Schaller A (2008) Direct defenses in plants and their induction by wounding and insect herbivores. In: Induced Plant Resistance to Herbivory(ed Schaller A.), pp. 7-29. Springer, New York.

James DG, Grasswitz TR (2005) Field attraction of parasitic wasps, Metaphycus spp. and Anagrus spp., to synthetic herbivore-induced plant volatiles. BioControl, 50, 871-880.

Karban R, Baxter KJ (2001) Induced resistance in wild tobacco with clipped sagebrush neighbors: the role of herbivore behavior. Journal of Insect Behavior, 14, 147-156.

Kerchev PI, Fenton B, Foyer CH, Hancock RD (2012) Plant responses to insect herbivory: interactions between photosynthesis, reactive oxygen species and hormonal signalling pathways. Plant, Cell \& Environment, 35, 441453.

Kessler A, Baldwin IT (2001) Defensive function of herbivoreinduced plant volatile emissions in nature. Science, 291, 2141-2144.

Kessler A, Baldwin IT (2004) Herbivore-induced plant vaccination. Part I. The orchestration of plant defenses in nature and their fitness consequences in the wild tobacco Nicotiana attenuata. The Plant Journal, 38, 639-649.

Koo AJK, Howe GA (2009) The wound hormone jasmonate. Phytochemistry, 70, 1571-1580.

Koo AJK, Gao X, Jones AD, Howe GA (2009) A rapid wound signal activates the systemic synthesis of bioactive jasmonates in Arabidopsis. The Plant Journal, 59, 974-986.

Koornneef A, Pieterse CMJ (2008) Cross talk in defense signaling. Plant Physiology, 146, 839-844.

Lancashire PD, Bleiholder H, Vandenboom T et al. (1991) A uniform decimal code for growth-stages of crops and weeds. The Annals of Applied Biology, 119, 561-601.

Lee S, Badieyan S, Bevan DR et al. (2010) Herbivore-induced and floral homoterpene volatiles are biosynthesized by a single P450 enzyme (CYP82G1) in Arabidopsis. Proceedings of the National Academy of Sciences of the United States of America, 107, 21205-21210.

Lorenzo O, Piqueras R, Sanchez-Serrano JJ, Solano R (2003) ETHYLENE RESPONSE FACTOR1 integrates signals from ethylene and jasmonate pathways in plant defense. The Plant Cell, 15, 165-178.

Lorenzo O, Chico JM, Sanchez-Serrano JJ, Solano R (2004) Jasmonate-insensitive1 encodes a MYC transcription factor essential to discriminate between different jasmonate-regulated defense responses in Arabidopsis. The Plant Cell, 16, 19381950.

Mathur V, Ganta S, Raaijmakers CE et al. (2011) Temporal dynamics of herbivore-induced responses in Brassica juncea and their effect on generalist and specialist herbivores. Entomologia Experimentalis et Applicata, 139, 215-225.

Mathur V, Tytgat TOG, de Graaf R et al. (2013) Dealing with double trouble: consequences of single and double herbivory in Brassica juncea. Chemoecology, 23, 71-82.

Matsui K (2006) Green leaf volatiles: hydroperoxide lyase pathway of oxylipin metabolism. Current Opinion in Plant Biology, 9, 274-280.
Matsui K, Wilkinson J, Hiatt B, Knauf V, Kajiwara T (1999) Molecular cloning and expression of Arabidopsis fatty acid hydroperoxide lyase. Plant \& Cell Physiology, 40, 477-481.

Mattiacci L, Dicke M, Posthumus MA (1994) Induction of parasitoid attracting synomone in brussel sprouts plants by feeding of Pieris brassicae larvae: role of mechanical damage and herbivore elicitor. Journal of Chemical Ecology, 20, 2229-2247.

Mayhew PJ (2001) Herbivore host choice and optimal bad motherhood. Trends in Ecology \& Evolution, 16, 165-167.

McCormick AC, Unsicker SB, Gershenzon J (2012) The specificity of herbivore-induced plant volatiles in attracting herbivore enemies. Trends in Plant Science, 17, 303-310.

Muller PY, Janovjak H, Miserez AR, Dobbie Z (2002) Processing of gene expression data generated by quantitative realtime RT-PCR. BioTechniques, 32, 1372-1379.

Mumm R, Dicke M (2010) Variation in natural plant products and the attraction of bodyguards involved in indirect plant defense. Canadian Journal of Zoology, 88, 628-667.

Mumm R, Burow M, Bukovinszkine'Kiss G et al. (2008a) Formation of simple nitriles upon glucosinolate hydrolysis affects direct and indirect defense against the specialist herbivore, Pieris rapae. Journal of Chemical Ecology, 34, 1311-1321.

Mumm R, Posthumus MA, Dicke M (2008b) Significance of terpenoids in induced indirect plant defence against herbivorous arthropods. Plant Cell \& Environment, 31, 575-585.

Naur P, Petersen BL, Mikkelsen MD et al. (2003) CYP83A1 and CYP83B1, two nonredundant cytochrome P450 enzymes metabolizing oximes in the biosynthesis of glucosinolates in Arabidopsis. Plant Physiology, 133, 63-72.

Ngumbi E, Chen L, Fadamiro H (2010) Electroantennogram (EAG) responses of Microplitis croceipes and Cotesia marginiventris and their lepidopteran hosts to a wide array of odor stimuli: correlation between EAG response and degree of host specificity? Journal of Insect Physiology, 56, 1260-1268.

Paré PW, Tumlinson JH (1999) Plant volatiles as a defense against insect herbivores. Plant Physiology, 121, 325-331.

Pichersky E, Sharkey TD, Gershenzon J (2006) Plant volatiles: lack of function or lack of knowledge? Trends in Plant Science, 11, 421.

Pierre PS, Jansen JJ, Hordijk CA et al. (2011) Differences in volatile profiles of turnip plants subjected to single and dual herbivory above- and belowground. Journal of Chemical Ecology, 37, 368-377.

Pieterse CMJ (2012) Prime time for transgenerational defense. Plant Physiology, 158, 545.

Pieterse CMJ, Dicke M (2007) Plant interactions with microbes and insects: from molecular mechanisms to ecology. Trends in Plant Science, 12, 564-569.

Pivnick KA, Jarvis BJ, Slater GP (1994) Identification of olfactory cues used in host-plant finding by diamondback moth, Plutella xylostella (Lepidoptera: Plutellidae). Journal of Chemical Ecolology, 20, 1407-1427.

van Poecke RMP, Posthumus MA, Dicke M (2001) Herbivoreinduced volatile production by Arabidopsis thaliana leads to attraction of the parasitoid Cotesia rubecula: chemical, behavioral, and gene-expression analysis. Journal of Chemical Ecology, 27, 1911-1928.

van Poecke RMP, Roosjen M, Pumarino L, Dicke M (2003) Attraction of the specialist parasitoid Cotesia rubecula to Arabidopsis thaliana infested by host or non-host herbivore species. Entomologia Experimentalis et Applicata, 107, 229-236. 
Poelman EH, Oduor AMO, Broekgaarden C et al. (2009) Field parasitism rates of caterpillars on Brassica oleracea plants are reliably predicted by differential attraction of Cotesia parasitoids. Functional Ecology, 23, 951-962.

Ratzka A, Vogel H, Kliebenstein DJ, Mitchell-Olds T, Kroymann J (2002) Disarming the mustard oil bomb. Proceedings of the National Academy of Sciences of the United States of America, 99, 11223-11228.

Reddy GVP (2012) Recent trends in the olfactory responses of insect natural enemies to plant volatiles. In: Biocommunication of Plants (eds Witzany G. \& Baluška F.), pp. 281-301. Springer-Verlag, Berlin Heidelberg.

Reddy GVP, Holopainen JK, Guerrero A (2002) Olfactory responses of Plutella xylostella natural enemies to host pheromone, larval frass, and green leaf cabbage volatiles. Journal of Chemical Ecology, 28, 131-143.

Rieu I, Powers SJ (2009) Real-time quantitative RT-PCR: design, calculations and statistical analysis. The Plant Cell, 21, 10311033.

Ruijter JM, Ramakers C, Hoogaars WMH et al. (2009) Amplification efficiency: linking baseline and bias in the analysis of quantitative PCR data. Nucleic Acids Research, 37, e45.

Schmelz EA, Alborn HT, Banchio E, Tumlinson JH (2003) Quantitative relationships between induced jasmonic acid levels and volatile emission in Zea mays during Spodoptera exigua herbivory. Planta, 216, 665-673.

Shiojiri K, Takabayashi J, Yano S, Takafuji A (2002) Oviposition preferences of herbivores are affected by tritrophic interaction webs. Ecology Letters, 5, 186-192.

Skibbe M, Qu N, Galis I, Baldwin IT (2008) Induced plant defenses in the natural environment: Nicotiana attenuata WRKY 3 and WRKY6 coordinate responses to herbivory. The Plant Cell Online, 20, 1984-2000.

Smid HM, van Loon JJA, Posthumus MA, Vet LEM (2002) GC-EAG-analysis of volatiles from Brussels sprouts plants damaged by two species of Pieris caterpillars: olfactory receptive range of a specialist and a generalist parasitoid wasp species. Chemoecology, 12, 169-176.

Sokal RR, Rohlf FJ (1995) Biometry: The Principles and Practice of Statistics in Biological Research, W.H. Freeman, New York, NY.

Soler R, Harvey JA, Kamp AFD et al. (2007) Root herbivores influence the behaviour of an aboveground parasitoid through changes in plant-volatile signals. Oikos, 116, 367-376.

Soler R, Ruben Badenes-Perez F, Broekgaarden C et al. (2012) Plant-mediated facilitation between a leaf-feeding and a phloem-feeding insect in a brassicaceous plant: from insect performance to gene transcription. Functional Ecology, 26, 156-166.

Steidle JLM, van Loon JJA (2003) Dietary specialization and infochemical use in carnivorous arthropods: testing a concept. Entomologia Experimentalis et Applicata, 108, 133-148.

Stewart-Jones A, Poppy GM (2006) Comparison of glass vessels and plastic bags for enclosing living plant parts for headspace analysis. Journal of Chemical Ecology, 32, 845-864.

Tholl D, Chen F, Petri J, Gershenzon J, Pichersky E (2005) Two sesquiterpene synthases are responsible for the complex mixture of sesquiterpenes emitted from Arabidopsis flowers. The Plant Journal, 42, 757-771.
Turlings TC, Fritzsche ME (1999) Attraction of parasitic wasps by caterpillar-damaged plants. Novartis Foundation symposium, 223, 21.

Turlings TCJ, Wäckers F (2004) Recruitment of predators and parasitoids by herbivore-injured plants. In: Advances in Insect Chemical Ecology (eds Cardé RT \& Millar JG), pp. 21-75. Cambridge University Press, Cambridge, UK.

Turlings TCJ, Tumlinson JH, Lewis WJ (1990) Exploitation of herbivore-induced plant odors by host-seeking parasitic wasps. Science, 250, 1251-1253.

Turlings TCJ, Tumlinson JH, Heath RR, Proveaux AT, Doolittle RE (1991) Isolation and identification of allelochemicals that attract the larval parasitoid, Cotesia marginiventris (Cresson), to the microhabitat of one of its hosts. Journal of Chemical Ecolology, 17, 2235-2251.

Vandesompele J, De Preter K, Pattyn F et al. (2002) Accurate normalization of real-time quantitative RT-PCR data by geometric averaging of multiple internal control genes. Genome biology, 3, RESEARCH0034.

Verhage A, van Wees SCM, Pieterse CMJ (2010) Plant immunity: it's the hormones talking, but what do they say? Plant Physiology, 154, 536-540.

Vet LEM (1999) Evolutionary aspects of plant-carnivore interactions. In: Insect-plant Interactions and Induced Plant Defence (eds Chadwick DJ, Goode JA), pp. 3-13. Novartis Foundation, John Wiley \& Sons, Chichester, UK.

Vet LEM, Dicke M (1992) Ecology of infochemical use by natural enemies in a tritrophic context. Annual Review of Entomology, 37, 141-172.

Vet LEM, Wäckers FL, Dicke M (1991) How to hunt for hiding hosts - the reliability-detectability problem in foraging parasitoids. Netherlands Journal of Zoology, 41, 202-213.

Vickerman DB, Trumble JT (1999) Feeding preferences of Spodoptera exigua in response to form and concentration of selenium. Archives of Insect Biochemistry and Physiology, 42, 64-73.

Vuorinen T, Nerg AM, Ibrahim MA, Reddy GVP, Holopainen JK (2004) Emission of Plutella xylostella-induced compounds from cabbages grown at elevated $\mathrm{CO} 2$ and orientation behavior of the natural enemies. Plant Physiology, 135, 1984-1992.

Warwick SI, Francis A, Al-Shehbaz IA (2006) Brassicaceae: species checklist and database on CD-Rom. Plant Systematics and Evolution, 259, 249-258.

Wittstock U, Kliebenstein DJ, Lambrix V, Reichelt M, Gershenson J (2003) Glucosinolate hydrolysis and its impact on generalist and specialist herbivores. In: Integrative Phytochemistry: From Ethnobotany to Molecular Ecology, Recent Advances in Phytochemistry (ed. Romeo JT), 37, pp. 101-125. Elsevier Science, Pergamon, Amsterdam.

Yamauchi Y, Hasegawa A, Taninaka A, Mizutani M, Sugimoto Y (2011) NADPH-dependent reductases involved in the detoxification of reactive carbonyls in plants. Journal of Biological Chemistry, 286, 6999-7009.

Zhang PJ, Broekgaarden C, Zheng SJ et al. (2013) Jasmonate and ethylene signaling mediate whitefly-induced interference with indirect plant defense in Arabidopsis thaliana. New Phytologist, 197, 1291-1299.

Zheng SJ, Zhang PJ, van Loon JJA, Dicke M (2011) Silencing defense pathways in arabidopsis by heterologous gene sequences from Brassica oleracea enhances the performance of a specialist and a generalist herbivorous insect. Journal of Chemical Ecology, 37, 818-829. 
V.M. designed and carried out experiments and wrote the study, T.O.G. Tytgat designed and carried out experiments and co-authored the study, C.A.H. performed the volatile analyses, H.R.H. carried out part of the gene expression analysis, J.J.J. performed the multivariate analyses of the volatile data sets, A.S.R., J.A.H., L.E.M.V. and N.M.van D. supervised and advised the first author during the experiments and commented on earlier versions of the study.

\section{Data accessibility}

Data from the insect preference bioassay, and volatile and gene expression analyses are uploaded as online supplemental material.

\section{Supporting information}

Additional supporting information may be found in the online version of this article.

Fig. S1 Olfactometer set-up for the insect preference test.

Fig. S2 RT-qPCR on marker genes for hormonal pathways.

Fig. S3 RT-qPCR on volatile biosynthetic genes.

Fig. S4 RT-qPCR on sulfur-containing volatile biosynthetic genes.

Appendix 1 Data S1 Volatile Analysis.

Appendix 2 Data S2 qPCR analysis.

Appendix 3 Data S3 Insect preference experiments 